\title{
Management of colorectal laterally spreading tumors: a systematic review and meta-analysis
}

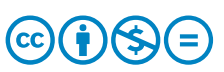

\author{
Authors \\ Institutions \\ 1 Gastroenterology Department, Centro Hospitalar de \\ Lisboa Central, Lisbon, Portugal \\ 2 Gastroenterology Department, Centro Hospitalar de \\ Leiria, Leiria, Portugal \\ 3 Department of Gastroenterology and Hepatology, \\ Westmead Hospital, Sydney, New South Wales, Australia \\ 4 Gastroenterology Department, Portuguese Oncology \\ Institute of Porto, Porto, Portugal \\ 5 CINTESIS/MEDCIDS, Porto Faculty of Medicine, Portugal \\ 6 Westmead Clinical School, University of Sydney, New \\ South Wales, Australia
}

Pedro Russo ", , Sandra Barbeiro*,2, Halim Awadie”, Diogo Libânio4, Mario Dinis-Ribeiro ${ }^{4,5}$, Michael Bourke ${ }^{3,6}$

submitted 22.1.2018

accepted after revision 4.7 .2018

Bibliography

DOI https://doi.org/10.1055/a-0732-487 |

Endoscopy International Open 2019; 07: E239-E259

(c) Georg Thieme Verlag KG Stuttgart · New York

ISSN 2364-3722

Corresponding author

Professor Michael Bourke, 106A/151 Hawkesbury Road,

Westmead, NSW, 2145

Fax: +61296333958

michael@citywestgastro.com.au

\section{ABSTRACT}

Objective and study aims To evaluate the efficacy and safety of different endoscopic resection techniques for laterally spreading colorectal tumors (LST).
Methods Relevant studies were identified in three electronic databases (PubMed, ISI and Cochrane Central Register). We considered all clinical studies in which colorectal LST were treated with endoscopic resection (endoscopic mucosal resection [EMR] and/or endoscopic submucosal dissection [ESD]) and/or transanal minimally invasive surgery (TEMS). Rates of en-bloc/piecemeal resection, complete endoscopic resection, R0 resection, curative resection, adverse events (AEs) or recurrence, were extracted. Study quality was assessed with the Newcastle-Ottawa Scale and a meta-analysis was performed using a random-effects model.

Results Forty-nine studies were included. Complete resection was similar between techniques (EMR 99.5\% [95\% Cl 98.6\%-100\%] vs. ESD 97.9\% [95\% Cl 96.1-99.2\%]), being curative in 1685/1895 (13 studies, pooled curative resection $90 \%, 95 \% \mathrm{Cl} 86.6-92.9 \%, \mathrm{I}^{2}=79 \%$ ) with non-significantly higher curative resection rates with ESD (93.6\%, $95 \%$ Cl $91.3-95.5 \%$, vs. $84 \% 95 \%$ Cl $78.1-89.3 \%$ with EMR). ESD was also associated with a significantly higher perforation risk (pooled incidence $5.9 \%, 95 \% \mathrm{Cl} 4.3-7.9 \%$, vs. EMR $1.2 \%$, $95 \% \mathrm{Cl} 0.5-2.3 \%$ ) while bleeding was significantly more frequent with EMR $(9.6 \%, 95 \% \mathrm{Cl} 6.5-13.2 \%$; vs. ESD $2.8 \%, 95 \% \mathrm{Cl} 1.9-4.0 \%)$. Procedure-related mortality was $0.1 \%$. Recurrence occurred in $5.5 \%$, more often with EMR $(12.6 \%$, $95 \%$ Cl $9.1-16.6 \%$ vs. ESD $1.1 \%$, $95 \%$ Cl $0.3-$ $2.5 \%)$, with most amenable to successful endoscopic treatment $(87.7 \%, 95 \% \mathrm{Cl} 81.1-93.1 \%)$. Surgery was limited to $2.7 \%$ of the lesions, $0.5 \%$ due to AEs. No data of TEMS were available for LST.

Conclusions EMR and ESD are both effective and safe and are associated with a very low risk of procedure related mortality.

\section{Introduction}

Lateral spreading tumors (LST) are considered important precursors of colorectal cancer [1]. LST were first described by Kudo as tumors with predominant spread within the mucosa while still relatively flat [2]. In the Paris consensus of 2002, LST

\footnotetext{
* Drs. Russo and Barbeiro: These authors contributed equally.
}

were defined as nonpolypoid lesions larger than $10 \mathrm{~mm}$ in width that typically extend laterally and circumferentially along the colonic wall, rather than vertically and were classified as type 0 -Ila [3]. LST are distinguished based on their granular or nongranular, homogenous or nonhomogenous appearance [1]. These lesions have been described in several studies with a wide range of definitions, not always concordant. Therefore, it 
is of paramount importance to establish an unambiguous and consensual definition for these lesions.

LST tend to preferentially spread superficially along the colonic wall rather than invading the submucosal layer and endoscopic resection can be effectively used as a minimally invasive treatment for the majority [4]. The flat morphology and potentially large dimensions of LST may render complete resection challenging [4]. The most common treatment approach for LST is endoscopic mucosal resection (EMR). However, en-bloc resection is usually restricted to lesions of less than $20 \mathrm{~mm}$ diameter. Piecemeal EMR of larger lesions is usually safe, but may hinder histologic assessment and lead to an increased risk of local recurrence. Endoscopic submucosal dissection (ESD) may overcome this problem, allowing dissection of larger lesions in one piece, although the procedure is technically more difficult, much more time-consuming, mandates multiday hospital admission and has an increased risk of perforation [5]. The majority of colorectal superficial lesions can be removed in a curative way by polypectomy or EMR; nevertheless, ESD should be considered for the removal of colorectal lesions with high suspicion of limited submucosal invasion, including those with depressed morphology or irregular/nongranular surface pattern, particularly in lesions larger than $20 \mathrm{~mm}$ [6].

Some recent meta-analyses have addressed endoscopic treatment outcomes of large non-pedunculated colorectal lesions and large colorectal polyps [7-9]. However, there are no published systematic reviews or meta-analyses focusing exclusively on LST.

In this systematic review and meta-analysis, the authors aimed to evaluate the efficacy and safety outcomes of endoscopic treatment of colorectal LST. Since many authors include purely sessile lesions in the LST group, it was also intended to study the clinical relevance of distinguishing LST from large sessile colorectal lesions.

\section{Methods}

A systematic review was conducted according to the preferred reporting items for systematic reviews and meta-analyses (PRISMA) statement [10]. The current systematic review was structured through the following PICO framework, addressing patients with LST, submitted to ESD/EMR/TEMS and evaluating the following outcomes: en-bloc/piecemeal, complete endoscopic resection, R0 and curative resections, adverse events and recurrence.

\section{Eligibility criteria}

All clinical studies published before June 15, 2016 in which colorectal LST were treated with endoscopic resection (EMR and ESD) and/or transanal minimally invasive surgery were considered. Only studies that reported at least one of the main treatment outcomes (en-bloc/piecemeal resection; complete endoscopic resection; R0 resection; curative resection; AEs or recurrence), were eligible for inclusion. Prospective and retrospective cohort studies, case-control studies and therapeutic clinical trials were included.
Manuscripts were excluded if they: (1) included sessile lesions (Paris 0-Is) and LST in the same group without a sub-analysis for LST treatment outcome; (2) included fewer than 20 LST (3) were animal or review studies; or (4) were non-English studies.

If there was suspicion of patient overlap between studies, only the study with the largest patient cohort for each of the outcomes was included.

\section{Definitions}

En-bloc resection was defined as resection of the lesion in one single piece and piecemeal resection as resection in more than one fragment.

Complete endoscopic resection was defined as the perception of the endoscopist that the lesion had been completely removed during endoscopy.

The resection was considered as R0 when histopathological examination confirmed free vertical and lateral margins, as R1 if the resection margins were involved or as $\mathrm{Rx}$ if the lateral or deep margins couldn't be evaluated due to piecemeal resection or coagulation effects.

Local recurrence implies that the patients were followed up for at least one colonoscopy after the index procedure and was defined as the finding of dysplastic tissue with histopathological confirmation detected at the site of previous endoscopic treatment. Resection was considered curative for adenomatous lesions or intramucosal carcinoma if $\mathrm{R} 0$ resection was achieved or if there was no recurrence at the end of follow up. For minimally invasive adenocarcinoma ( $\mathrm{sm} 1$ invasion $<1000 \mu \mathrm{m})$ resection was considered curative for well-differentiated tumors if R0 resection was achieved and there was no lymphovascular or perineural invasion.

Bleeding was classified into two subtypes: immediate and delayed. Immediate bleeding was defined as active bleeding that developed during the procedure. Delayed bleeding was defined as melena or bloody stools that occurred after completion of endoscopic resection. Bleeding was further classified as minor (when hemostasis required endoscopic procedures - hemoclip application/injection therapy, without a blood transfusion) or massive (when requiring blood transfusion and/or surgery) $[11-15]$. Bleeding during the resection procedure that was stopped spontaneously or with hemostatic forceps was not considered to be a complication. [5] In most cases, large visible exposed vessels or bleeding points were coagulated using hemostatic forceps and any remaining vessels visible after completed resection were also coagulated routinely to prevent delayed bleeding.

Perforation was immediate (diagnosed by endoscopic evidence of a definite mural defect with the visualization of an intraperitoneal organ or peritoneal/fat tissue) or delayed (diagnosed after a finished endoscopic resection by presence of free air on abdominal plain radiograph or during a computed tomogram) $[11,12,14,15]$. 


\section{Search strategy}

Relevant studies were identified in three electronic databases (MEDLINE through PubMed; ISI Web of Knowledge and Cochrane Central Register of Controlled Trials). The search was performed using the following query for PubMed: (polyp OR tumor OR tumour OR tumors OR lesion OR neoplasm OR adenoma) AND (non-pedunculated OR large OR flat OR "lateral spreading”; OR “laterally spreading”; OR LSL OR LST) AND (coIon OR rectum OR colorectal OR colorectal OR colonic OR rectal) AND (endoscopic AND (resection OR EMR OR ER OR mucosectomy OR endoscopic submucosal dissection OR ESD OR polypectomy OR transanal endoscopic microsurgery OR TEMS OR TEM OR TAMIS OR “transanal surgery"). The search terms for other databases were adapted from this query. Additional studies were identified by checking the list of references of all included studies and also review articles on this topic. The last search was performed on June 15, 2016.

\section{Study selection}

After removal of duplicates, two authors (PR, SB) independently screened all titles and abstracts for relevance. The full text of selected relevant studies was then evaluated by the same two researchers according to the inclusion criteria described above. A third author (MDR) intervened in case of disagreement.

\section{Quality evaluation and data extraction}

Data extraction was performed by PR, SB and HA. Another two reviewers (MDR and $\mathrm{MJB}$ ) independently checked the extracted data and disagreements were solved by consensus.

From each paper the following data were collected: (1) country; (2) publication year; (3) setting (single-center/multicenter); (4) enrollment period; (5) study design (prospective/ retrospective); (6) type of resection techniques (EMR/ESD/ TEMS); (7) operator (single/multiple; experienced/non-experienced); (8) definition of LST; (9) number of LST; (10) number of patients with LST; (11) mean/median age of the patients with LST; (12) gender distribution; (13) morphology of LST and subtypes (LSTG/LSTNG and LSTGH/LSTGM/LSTNGF/LSTNGPD); (14) mean size of LST; (15) size distribution (number of $\geq 10 \mathrm{~mm} / \geq 20 \mathrm{~mm} / \geq 30 \mathrm{~mm} / \geq 40 \mathrm{~mm}$ ); (16) site distribution (proximal/distal); (17) type of resection (en-bloc/piecemeal); (18) rate of complete endoscopic resection; (19) histology (R0 and curative resection); (20) rate of AE (bleeding, perforation, death, other); (21) average follow-up period (months); (22) rate of recurrence; (23) treatment of recurrence; and (24) rate of surgery (for unsuccessful complete resection, for non-curative resection, for $\mathrm{AE}$ or for recurrence). In some articles, added additional data provided by the authors were added.

Quality evaluation was performed by PR and HA using the Newcastle-Ottawa scale.

\section{Data synthesis and statistical analysis}

Raw data for each outcome (number of events and total) were collected allowing calculation of outcome prevalence and standard error. For meta-analysis, as most of the studies report prevalence rates between $0 \%$ and $100 \%$ (depending on the

\begin{tabular}{|c|c|c|c|}
\hline \multicolumn{2}{|c|}{$\begin{array}{c}\text { PubMed results } \\
1666\end{array}$} & $\begin{array}{l}\text { ISI results } \\
1892\end{array}$ & $\begin{array}{l}\text { Cochrane } \\
\text { results } 177^{*}\end{array}$ \\
\hline \multicolumn{4}{|c|}{ Combined results 3735} \\
\hline$\rightarrow$ & \multicolumn{3}{|c|}{ Removing duplicates } \\
\hline \multicolumn{4}{|c|}{$\begin{array}{l}\text { Results (titles and abstracts) } \\
\text { Pubmed } 1666 \text { ISI } 1023 \text { Cochrane } 130\end{array}$} \\
\hline$\rightarrow$ & \multicolumn{3}{|c|}{$\begin{array}{l}\text { Screening title and abstract - exclusion: } \\
\text { - Animal studies } \\
\text { - Not English, Portuguese or Spanish languages } \\
\text { - Not colon and/or rectum } \\
\text { - Not clinical study (case reports, reviews, } \\
\text { meta-analyses) }\end{array}$} \\
\hline \multicolumn{4}{|c|}{$\begin{array}{l}\text { Results (full text) } \\
\text { Pubmed } 425 \text { ISI } 434 \text { Cochrane } 14\end{array}$} \\
\hline$\rightarrow$ & \multicolumn{3}{|c|}{$\begin{array}{l}\text { Screening full text - exclusion: } \\
\text { - Not LST group } \\
\text { - Not at least one treatment outcome } \\
\text { - Not adenoma and/or T1 cancer and/or serrated } \\
\text { - } N<20 \\
\text { - Excluded familial polyposis syndrome, } \\
\text { inflammatory bowel disease }\end{array}$} \\
\hline \multicolumn{4}{|c|}{49 final results } \\
\hline \multicolumn{4}{|c|}{ *Cochrane trials database } \\
\hline
\end{tabular}

evaluated outcome), the double arcsine transformation (Freeman-Tukey) was used to adjust for variance. Double arcsine transformed proportions were then used for calculation of pooled proportions and were back-transformed for results presentation to allow easier interpretation.

Meta-analysis was performed with MetaXL and Open Metaanalyst using a random-effect model and heterogeneity was evaluated with Cochran's $Q$ test and $I^{2}$, a measure of inconsistency. A subgroup analysis was planned according to the resection method used (EMR or ESD). Sensitivity analysis was performed when substantial heterogeneity was detected. Publication bias was assessed visually with funnel plot for the primary outcome.

\section{Results}

\section{Study selection}

A total of 2819 studies were identified by the searches in PubMed (1666), ISI (1023) and Cochrane Register of Controlled Trials (130). After screening titles and abstracts, 873 studies were found to be eligible. After full-text analysis, 824 studies were excluded (812 did not fill the inclusion criteria; 10 had 
- Table 1 The main characteristics of the included studies.

\begin{tabular}{|c|c|c|c|c|c|}
\hline & $\begin{array}{l}\text { Period of enroll- } \\
\text { ment, years }\end{array}$ & $\begin{array}{l}\text { Number } \\
\text { of LST }\end{array}$ & Size of LST included, mm & Technical modifications & Quality $^{1}$ \\
\hline \multicolumn{6}{|l|}{ EMR } \\
\hline \multicolumn{6}{|l|}{ Prospective, multicenter } \\
\hline \multicolumn{6}{|l|}{ Australia } \\
\hline Burgess NG, 2014 [69] & $2008-2013$ & 873 & $\geq 20$ & & 7 \\
\hline Moss A, 2015 & $2008-2012$ & 747 & $\geq 20$ & & 6 \\
\hline \multicolumn{6}{|l|}{ Italy } \\
\hline Conio M, 2010 [16] & $2000-2007$ & 136 & $\geq 20$ & Cap EMR & 6 \\
\hline \multicolumn{6}{|l|}{ Greece } \\
\hline Fasoulas K, 2012 [18] & $2005-2010$ & 49 & $\geq 30$ & & RCT \\
\hline \multicolumn{6}{|l|}{ Czech } \\
\hline Urban O, 2008 [4] & $2002-2006$ & 138 & $>10$ & & 6 \\
\hline \multicolumn{6}{|c|}{ Prospective, single-center } \\
\hline \multicolumn{6}{|l|}{ Germany } \\
\hline Belle S, 2012 [25] & $2006-2007$ & 70 & $>12$ & STEP EMR & 6 \\
\hline \multicolumn{6}{|c|}{ Retrospective, single center } \\
\hline \multicolumn{6}{|l|}{ Japan } \\
\hline Yoshikane H, 1999 [17] & $1996-1998$ & 23 & NR & Cap EMR & 8 \\
\hline Uraoka T, 2005 [14] & $1998-2003$ & 223 & $\leq 30$ & & 6 \\
\hline Tanaka,2001 [70] & NR & 120 & $\geq 20$ & & 6 \\
\hline Tamura S, 2004 [71] & $1989-2002$ & 67 & NR & & 6 \\
\hline \multicolumn{6}{|l|}{ China } \\
\hline Huang Y, 2009 [38] & $2000-2007$ & 111 & $\geq 10$ & & 6 \\
\hline \multicolumn{6}{|l|}{ Taiwan } \\
\hline Su MY, 2008 [72] & $1999-2005$ & 201 & $>10$ & & 6 \\
\hline \multicolumn{6}{|l|}{ UK } \\
\hline Hurlstone DP, 2004 [73] & $1999-2003$ & 82 & $\geq 10$ & & 6 \\
\hline Arebi N, 2007 [27] & $1997-2005$ & 48 & $\geq 20$ & & 6 \\
\hline \multicolumn{6}{|l|}{ United States } \\
\hline Kim HG, 2014 [26] & $2009-2014$ & 80 & $\mathrm{LST} \geq 20$ & Underwater EMR & 7 \\
\hline Binmoller KF, 2015 [19] & NR & 53 & $>20$ and $<40$ & Underwater EMR & 5 \\
\hline \multicolumn{6}{|l|}{ ESD } \\
\hline \multicolumn{6}{|c|}{ Prospective, single-center } \\
\hline \multicolumn{6}{|l|}{ Japan } \\
\hline Ritsuno H, 2014 [53] & $2010-2011$ & 50 & $>20$ & ESD S-O clip traction & $\mathrm{RCT}$ \\
\hline \multicolumn{6}{|c|}{ Retrospective, multicenter } \\
\hline \multicolumn{6}{|l|}{ Japan } \\
\hline Mizushima T, 2015 [54] & $2011-2013$ & 113 & NR & & 6 \\
\hline
\end{tabular}


> Table 1 (Continuation)

\begin{tabular}{|c|c|c|c|c|c|}
\hline & $\begin{array}{l}\text { Period of enroll- } \\
\text { ment, years }\end{array}$ & $\begin{array}{l}\text { Number } \\
\text { of LST }\end{array}$ & Size of LST included, mm & Technical modifications & Quality $^{1}$ \\
\hline \multicolumn{6}{|c|}{ Retrospective, single center } \\
\hline \multicolumn{6}{|l|}{ Japan } \\
\hline Uraoka T, 2010 [56] & $2006-2008$ & 37 & LSTG $\geq 30$ and $L S T N G \geq 20$ & & 8 \\
\hline Okamoto K, 2012 [59] & $2010-2011$ & 30 & $\begin{array}{l}>20 \text { LSTNG; } \\
>30 \text { LSTG }\end{array}$ & Traction vs. no traction & 7 \\
\hline Suzuki S, 2014 [13] & $2009-2013$ & 290 & NR & & 6 \\
\hline Niimi K, 2010 [11] & $2000-2008$ & 245 & NR & & 6 \\
\hline Nishiyama H, 2010 [12] & $2002-2008$ & 204 & $>20$ & & 6 \\
\hline Hotta K, 2012 [58] & $2000-2010$ & 201 & NR & & 6 \\
\hline Hisabe T, 2012 [57] & $2003-2011$ & 162 & NR & & 6 \\
\hline Sakamoto T, 2014 [49] & $2005-2012$ & 139 & $>20$ & & 6 \\
\hline Nawata Y, 2014 [61] & $2010-2013$ & 137 & $18-123$ & & 6 \\
\hline Toyonaga T, 2010 [55] & $2009-2010$ & 132 & NR & & 6 \\
\hline Makino T, 2015 [62] & $2009-2013$ & 58 & $>10$ & & 5 \\
\hline Okamoto K, 2013 [60] & $2010-2012$ & 30 & $28-45$ & $\mathrm{M} 2-\mathrm{SB}$ & 5 \\
\hline \multicolumn{6}{|l|}{ Korea } \\
\hline Bae JH, 2015 [15] & $2007-2014$ & 153 & $\geq 30$ & ESD and ESD with snaring & 8 \\
\hline EJ Lee 2011 [63] & $2006-2010$ & 358 & $\geq 20$ & & 7 \\
\hline Hong MJ, 2015 [65] & $2010-2013$ & 113 & $>20$ & & 7 \\
\hline Jung DH, 2015 [66] & $2009-2014$ & 163 & NR (subgroup $\geq 100$ ) & & 6 \\
\hline Yoon JY, 2012 [64] & $2008-2011$ & 101 & $\geq 10$ & & 6 \\
\hline Kim ES, 2011 [23] & $2007-2009$ & 81 & $\geq 10$ & & 6 \\
\hline \multicolumn{6}{|l|}{ China } \\
\hline Xu MD, 2013 [41] & $2008-2011$ & 137 & $\geq 20$ & & 8 \\
\hline Cong Z], 2015 [36] & $2003-2007$ & 177 & $\geq 30$ & & 7 \\
\hline Zhou PH, 2009 [67] & $2006-2007$ & 74 & $\geq 20$ & & 6 \\
\hline Tang XW, 2016 [30] & $2010-2014$ & 36 & $\geq 40$ & & 5 \\
\hline \multicolumn{6}{|l|}{ Turkey } \\
\hline Hulagu S, 2013 [20] & $2006-2011$ & 44 & $\geq 20$ & & 5 \\
\hline \multicolumn{6}{|l|}{ Austria } \\
\hline Berr F, 2014 [24] & $2009-2012$ & 39 & $\geq 20$ & & 5 \\
\hline \multicolumn{6}{|l|}{ UK } \\
\hline Hurlstone DP, 2007 [22] & $2004-2006$ & 28 & $\geq 20$ & & 6 \\
\hline \multicolumn{6}{|l|}{ Germany } \\
\hline Probst A, 2012 [5] & $2004-2011$ & 74 & $>15$ & & 9 \\
\hline \multicolumn{6}{|l|}{ Italy } \\
\hline Repici A, 2013 [68] & $2010-2011$ & 40 & $33-80$ & & 6 \\
\hline ESD vs. EMR & & & & & \\
\hline
\end{tabular}


- Table 1 (Continuation)

\begin{tabular}{|c|c|c|c|c|c|}
\hline & $\begin{array}{l}\text { Period of enroll- } \\
\text { ment, years }\end{array}$ & $\begin{array}{l}\text { Number } \\
\text { of LST }\end{array}$ & Size of LST included, mm & Technical modifications & Quality \\
\hline \multicolumn{6}{|c|}{ Retrospective, single center } \\
\hline \multicolumn{6}{|l|}{ Japan } \\
\hline lizuka H,2009 [21] & $2000-2004$ & 70 & $\geq 20$ & & 7 \\
\hline Terasaki, 2011 [74] & $2006-2009$ & 267 & $>20$ & ESD/hybridESD vs. EMR/EMRP & 6 \\
\hline \multicolumn{6}{|l|}{ India } \\
\hline Tajika M, 2011 [75] & $1995-2009$ & 106 & $>20$ & & 7 \\
\hline \multicolumn{6}{|l|}{ UK } \\
\hline Hurlstone DP, 2006 [52] & $1999-2004$ & 20 & $16-58$ & Salvage EMR/ESD & 6 \\
\hline
\end{tabular}

risk of patient overlap; two due to conflicting data) while 49 studies were included. A flow chart of the selection process is shown in > Fig. 1.

\section{Study characteristics}

The main characteristics of the included studies are listed in - Table 1. Most of the studies were single-center (43, 87.8\%), and six (12.2\%) were multicenter. The majority (42, $85.7 \%$ ) were retrospective. Sixteen studies evaluated EMR, including two studies of cap-assisted EMR and two studies including underwater EMR (one them for recurrent LST); 29 studies reported one or more outcomes for ESD; four studies reported outcomes for both techniques. A total of 27 studies included exclusively laterally spreading tumors, while a sub-analysis for LST was available in the other 22 studies.

Inclusion criteria regarding lesion size varied between the studies: lesions $\geq 10 \mathrm{~mm}-7$ studies; $\geq 12 \mathrm{~mm}-1$ study; $\geq 15 \mathrm{~mm}-1$ study; 20 studies included lesions $\geq 20 \mathrm{~mm}$ (one of them $\leq 40 \mathrm{~mm}$ ); 3 studies included lesions $\geq 30 \mathrm{~mm}$ and one $\geq 40 \mathrm{~mm} ; 2$ studies included LST-NG $\geq 20 \mathrm{~mm}$ and LST-G $\geq 30 \mathrm{~mm}$; one study included lesions $\leq 30 \mathrm{~mm}$; the other studies did not specify inclusion criteria based on size.

En-bloc/piecemeal resection was reported in 12 EMR and 17 ESD studies. Complete endoscopic resection according to our definition was available in 20 studies ( 8 EMR and 12 ESD). R0 rates were assessed in three EMR and 14 ESD studies, while data on the recurrence was given in 15 EMR and 15 ESD studies. We could extrapolate curative resection according to our criteria in six EMR and eight ESD studies. Twelve studies reported global AE rate for EMR; 13 reported perforation and 14 bleeding. The same information was available for ESD in 21, 25 and 19 studies, respectively.

Information regarding surgical intervention was available in 16 EMR studies (12 for surgery of recurrence; 14 for AE and 12 for incomplete/non-curative resection) and 21 ESD studies (11 for recurrence, 19 for AEs and 10 for incomplete/non-curative resection).

\section{En-bloc resection}

Overall, pooled en-bloc resection rate was $75.6 \%(95 \% \mathrm{Cl}$ $60.4 \%-88.2 \%, 1^{2}=99 \%$ ), being significantly higher with ESD (93.7\%, 95\% Cl 89.3-95.6\%)-versus EMR $(37.7 \%, 95 \% \mathrm{Cl}$ $23.0 \%-53.5 \%$ ) ( Fig. 2a). Conio M. et al. [16] applied the cap-assisted EMR technique in all of the lesions $(\geq 20 \mathrm{~mm})$ which explains the $0 \%$ en-bloc resection in this study. The study by Yoshikane $\mathrm{H}$. et al. [17] also evaluated cap-assisted EMR but included lesions $\geq 10 \mathrm{~mm}$, allowing $65.2 \%$ en-bloc resection. The lower en-bloc rate in Fasoulas K. et al. [18], is explained by the inclusion of larger lesions ( $\geq 30 \mathrm{~mm}$ ). In contrast, Binmoller K.F. et al. [19], resected $55 \%$ of the lesions (20-40 mm) en-bloc using the underwater EMR technique. The two studies with lower ESD en-bloc rate were Hulagu S. et al. and lizuka $\mathrm{H}$. et al. $[20,21]$. Hulagu S. et al. [20], justified their lower rate of enbloc resection with the higher rate of partial prior endoscopic resection (polypectomy) and scar tissue formation. The high rate of deep submucosal cancer may have precluded better results in the Lizuka et al. study [21]. En-bloc resection rates were not significantly different for LST-G and LST-NG for both ESD and EMR (ESD: 11 studies, OR $0.83795 \% \mathrm{Cl} 0.534-1.312, \mathrm{I}^{2}=$ $0 \%$; EMR: 4 studies, OR $0.52995 \% \mathrm{Cl} 0.410-0.683, \mathrm{I}^{2}=25 \%$ ).

The rate of en-bloc resection in EMR studies was not significantly different in studies including lesions $>10 \mathrm{~mm}$ and $>20 \mathrm{~mm}$; only two studies using the $30-\mathrm{mm}$ threshold were found and the rate of en-bloc resection was significantly higher in the Study including lesions $<30 \mathrm{~mm}(53,8 \% 95 \% \mathrm{Cl} 47.2-$ $60.3 \%$ versus $22.4 \% 95 \% \mathrm{Cl} 11.7-35.3 \%$ ). The rate of ESD enbloc resection was not influenced by the size of the lesions included, being $>90 \%$ in all subgroups (>20 mm: 6 studies, $92.8 \%$ $95 \% \mathrm{Cl} 86.8$ - 97.5\%;>30 mm: 4 studies, $91.9 \% 95 \% \mathrm{Cl} 83.9-$ 98.1\%; > 40 mm: 1 study,> 100 mm: 1 study, $93.395 \%$ Cl $88-$ 96.7\%; not reported: 5 studies, $93.5 \% 95 \%$ Cl 85.2-99.5\%). In a subgroup analysis, according to the size of included lesions, the rate of en-bloc resection was significantly higher in ESD studies whether they included lesions $>20 \mathrm{~mm}$ or $>30 \mathrm{~mm}$. 


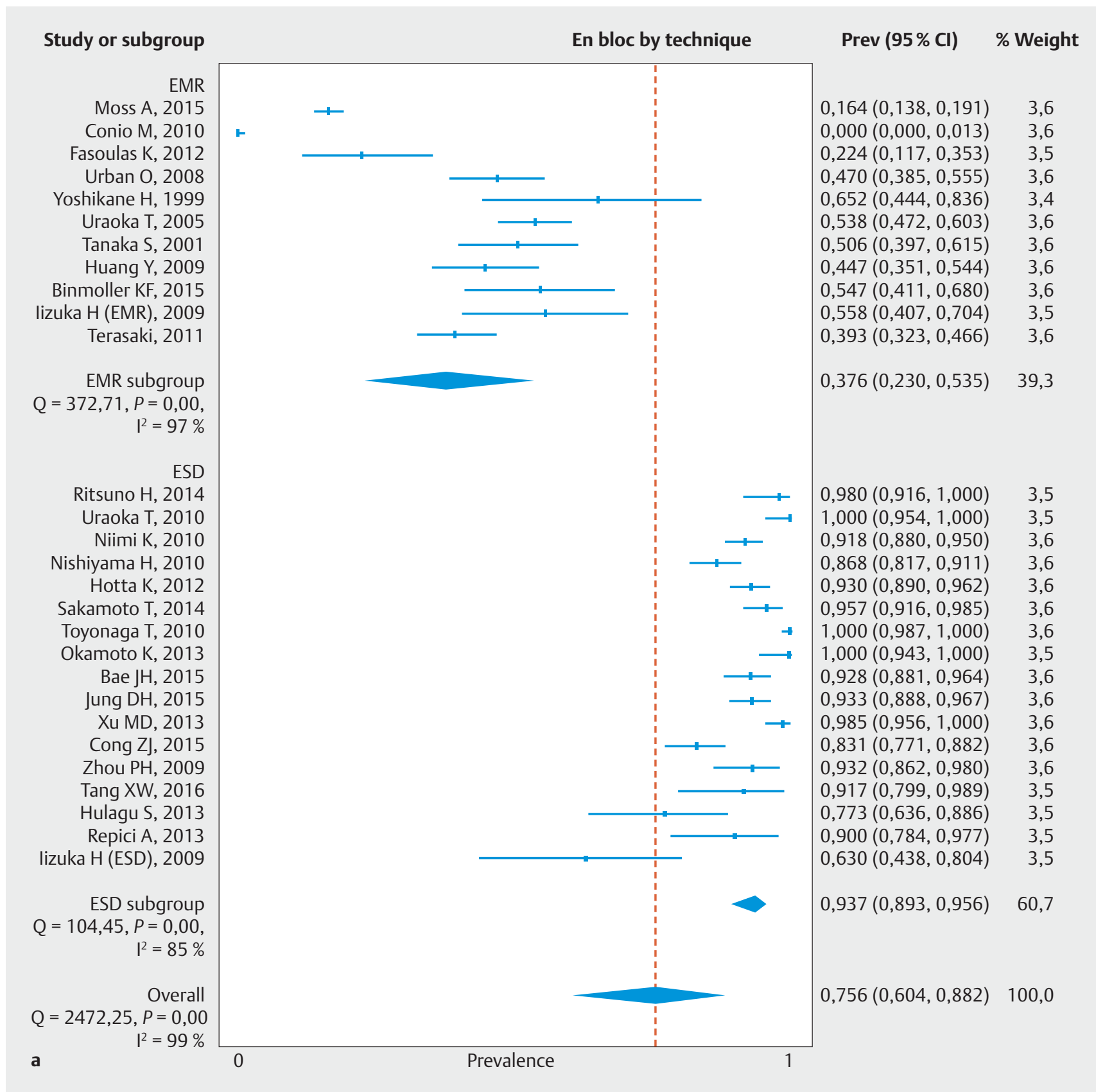

- Fig. 2a Rate of en-bloc resection by technique.

\section{Complete resection and $\mathrm{R} 0$ resection}

Complete endoscopic resection by endoscopist opinion was achieved in $98.6 \%$ (95\% Cl 97.6-99.4\%, $\mathrm{I}^{2}=58 \%$ ), being similar with EMR and ESD ( $\triangleright$ Fig. 2 b). Pooled R0 resection was $79.2 \%$ (95\% 68.3-88.4\%, $1^{2}=79.2$ ), being significantly higher with ESD (86.4\% 95\% Cl 79.5-91.7\% vs. EMR 36.2\% 95\% Cl $31.2-$ $41.8 \%$ ), Once again the study by Lizuka, 2009, showed lower ESD complete endoscopic and $\mathrm{R} 0$ resection rates, possibly because of the high incidence of deep submucosal invasion [21]. In the Hurlstone ESD study [22], a low R0 rate $(67,9 \%)$ is in correlation with a low en-bloc rate $(78,6 \%$-includes non-LST lesions).
There were no statistically significant differences between R0 resection for LST-G and LST-NG (OR $1.082 \mathrm{Cl} 0.770-1.519$, $\left.\mathrm{I}^{2} 0 \%\right)$. R0 resection was achieved in $673 / 763$ (83.5\%) of LST-G and $347 / 417$ (83.2\%) of LST-NG ( $\mathbf{F i g . 2 c}$ ).

\section{Curative resection}

Overall, endoscopic resection of LST was curative in 1685/1895 (13 studies, pooled curative resection $90 \%$, $95 \% \mathrm{Cl} 86.6-$ $\left.92.9 \%, I^{2}=79 \%\right)$. Subgroup analysis according to the technique used showed significantly higher curative resection rates with ESD (93.6\% 95\% Cl 91.3-95.5\%, versus $84 \% 95 \% \mathrm{Cl} 78.1-$ $89.3 \%$ with EMR) ( $\triangleright$ Fig. 2 d). It is worth highlighting the study 


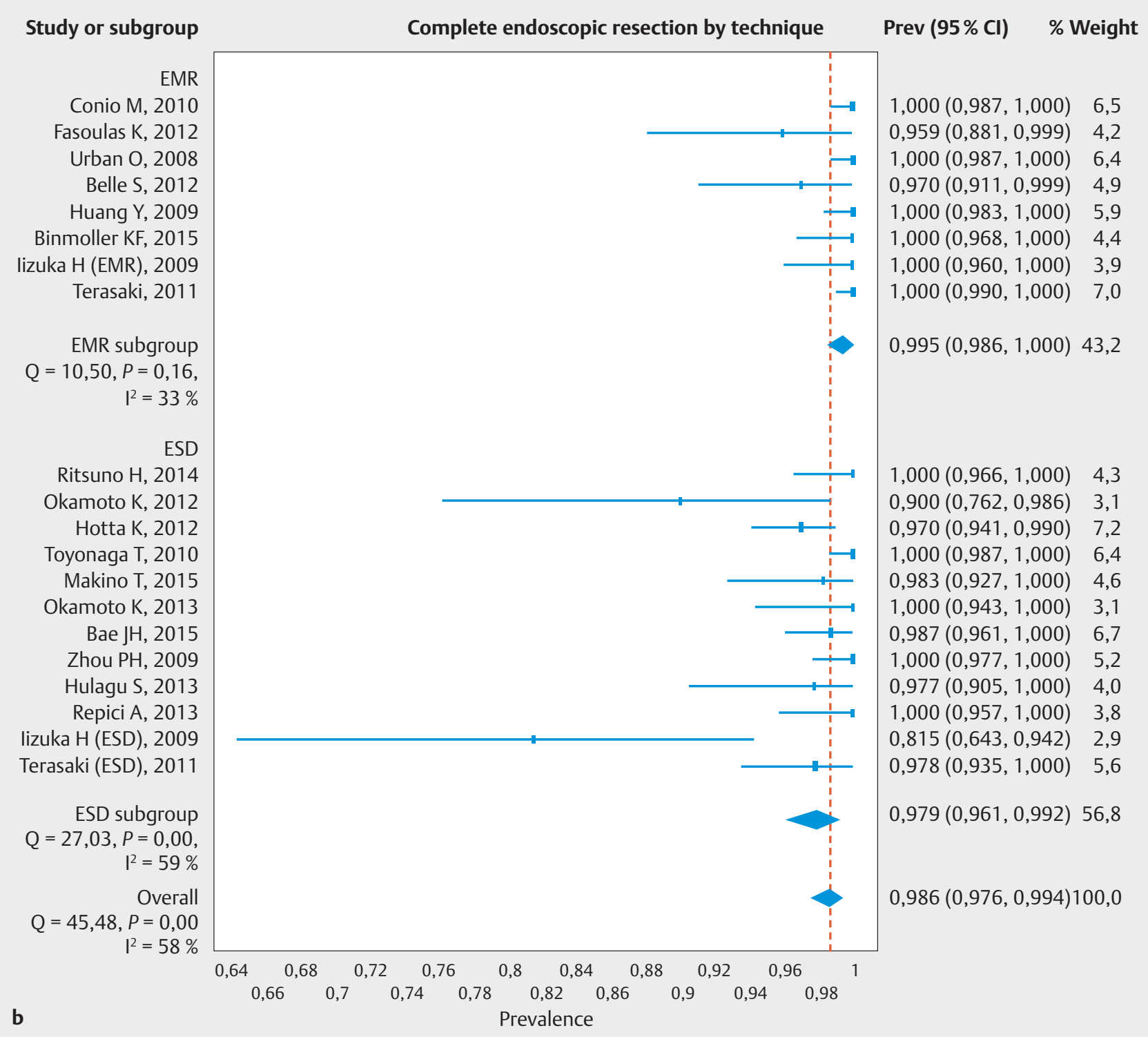

- Fig. 2b Rate of complete endoscopic resection by technique.

by Fasoulas et al. [18], with the lowest curative resection rates among the EMR studies that included larger lesions ( $\geq 30 \mathrm{~mm})$.

\section{Submucosal invasion}

Prevalence of cancer was similar between the EMR and the ESD series, despite the trend towards more submucosal invasion in the ESD series (EMR 5.6\% 95\% Cl 2.0-10.2\% versus ESD $11 \%$ $95 \% \mathrm{Cl} 5.9-17.0 \%$ ) ( $\mathbf{F i g . 2 e}$ ). If we exclude the outliers (studies with a prevalence of submucosal invasion $>20 \%$ ), (Terasaki EMR; Uraoka T; Terasaki ESD, Yoon JY) the difference is still not significant (EMR $4.1 \% 95 \% \mathrm{Cl} 2.3-6.2 \%$ versus ESD $5.8 \% 95 \%$ Cl 4.4-9.6\%). LST-G presented less submucosal invasion (39/ $503)$ when compared to LST-NG (OR $0.4795 \%$ CI $0.29-0.74)$.

\section{Adverse events}

Resection of LSTs was associated with a pooled incidence of overall AEs of $9.2 \%$ (7.2-11.5\%). No significant differences between EMR and ESD were found ( $\mathbf{F i g . 3 a ) . ~}$

Overall, pooled perforation rate was $4.1 \%$ (95\% Cl $2.7-$ $5.6 \%, I^{2}=84 \%$ ). However, ESD was associated with a significantly higher perforation risk (pooled incidence 5.9\% 95\% Cl $4.3-$ $7.9 \%$, versus EMR $1.2 \% 95 \% \mathrm{Cl} 0.5-2.3 \%$ ) ( Fig. 3b). The studies by Kim [23] and Berr [24] registered the larger number of perforations. The latter study evaluated the untutored learning of ESD in a series of 50 lesions including 33 colorectal LST and $15.2 \%$ of the colorectal procedures were complicated with perforation. If this study is excluded the perforation rate is $5.7 \%$.

On the other hand, pooled bleeding rate was $5.3 \%(95 \% \mathrm{Cl}$ $3.6-7.2 \%)$ and was significantly more frequent with EMR (9.6\% 95\% Cl 6.5-13.2\%; versus ESD $2.8 \% 95 \% \mathrm{Cl} 1.9-4.0 \%$ ) 


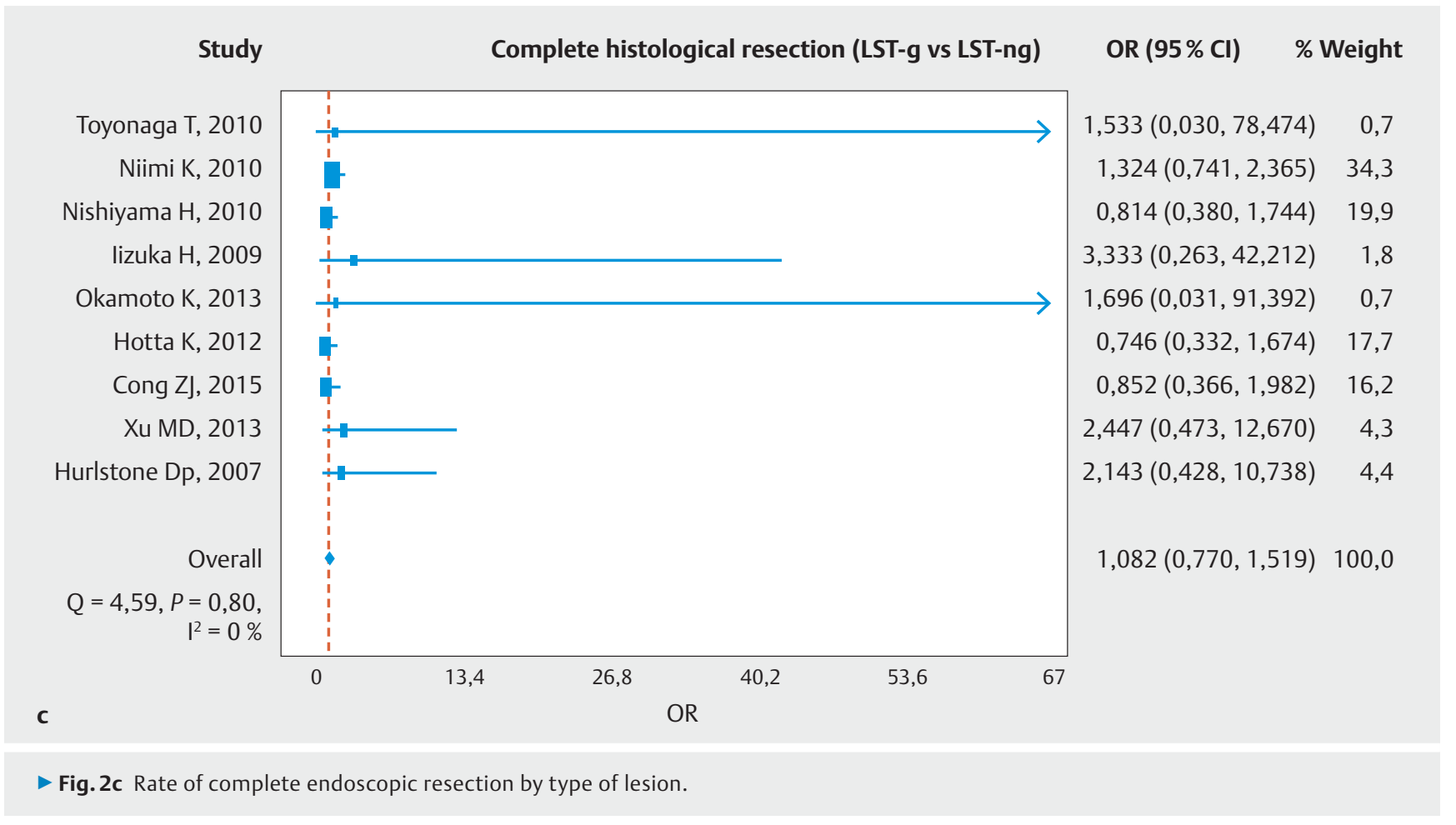

( $\triangleright$ Fig.3c). Bleeding rate was particularly high in the study by Belle et al. [25], in which 25/66 patients required hemostasis with clips. If this atypical study is excluded, the bleeding rate is $4.8 \%$ (95\% Cl 3.4\%-6.5\%) and remains significantly higher with EMR.

If we only consider major bleeding there were no statistically significant differences between both techniques (EMR $0.2 \%$ $95 \% \mathrm{Cl} 0-0.04 \%$ versus ESD $0.4 \% 95 \% \mathrm{Cl} 0.1-0.7 \%)$. Immediate minor bleeding was significantly less frequent for ESD $(0.5 \%$ $95 \% \mathrm{Cl} 0.1-1.0 \%$ versus EMR: $7.7 \% 95 \% \mathrm{Cl} 1.5-15.9 \%)$. No differences were found between EMR and ESD for delayed major or minor bleeding.

Coagulation syndrome was evaluated in five studies including 718 patients ( 3 EMR, 1 EMR\&ESD and 1 ESD studies) and pooled rate was $3.1 \%\left(95 \% \mathrm{Cl} 0.3-8.0 \%, \mathrm{I}^{2}=86 \%\right)$.

One patient died following EMR due to complications of acute myocardial infarction [4]. Pooled procedure-related mortality was $0.1 \%\left(95 \% \mathrm{Cl} 0.0-0.3 \%, \mathrm{I}^{2}=0 \%\right)$.

Between both subtypes of LST there were no differences in perforation or bleeding rates. In LST-G, perforation occurred in $52 / 906$ (5.74\%) while in LST-NG it occurred in 20/446 (4.48\%) (OR 1.072, $95 \% \mathrm{Cl} 0.497-2.310, \mathrm{I}^{2}=36.94 \%$ ). Bleeding was more frequent with LST-G $(26 / 585-4.44 \%)$ compared with LST-NG (11/424-2.59\%) (OR 2.460, $95 \%$ Cl 0.476-12.729, $\left.\mathrm{I}^{2}=75.05 \%\right)$.

\section{Recurrence}

Overall, recurrence occurred in 5.5\% (95\% Cl 3.0-8.6\%) being significantly more frequent with EMR $(12.6 \% 95 \% \mathrm{Cl} 9.1-$ $16.6 \%)$ vs. ESD ( $1.1 \% 95 \% \mathrm{Cl} 0.3-2.5 \%)$. However, the majority of the recurrences were amenable to successful endoscopic treatment $(87.7 \%, 95 \% \mathrm{Cl} 81.1-93.1 \%)$. The timing of endoscopic surveillance was heterogeneous between the studies which may have affected the rate of early recurrence. Mean follow-up ranged from 9.2 to 60.8 months.

The retrospective study from Kim et al. evaluated the efficacy of underwater versus conventional EMR for the treatment of recurrence after piecemeal resection of LST [26]. Underwater EMR was successful in 18/20 patients and conventional EMR was successful in only 20/33 [26]. Two EMR studies demonstrated the highest recurrence rates, Arebi N. et al. [27] (40.9\%, 95\% Cl 26.7-55.9\%) and Fasoulas et al. [18] (27.3\%, $95 \% \mathrm{Cl} 15.0-41.5 \%)$. The latter, probably because larger lesions $(\geq 30 \mathrm{~mm})$ were included with only $22.4 \%$ removed enbloc [18].

\section{Surgery rates}

Overall, LSTs submitted to endoscopic resection led to surgery in $2.7 \%$ (95\% Cl $1.8-3.8 \%)$, without significant differences in surgery rates according to the endoscopic resection technique despite a trend to higher surgery rates with EMR ( $\bullet$ Fig.4a). Concerning the reasons for surgery:

- 33 studies involving 3857 patients reported 12 surgeries due to AEs (pooled rate was $0.5 \%, 95 \% \mathrm{Cl} 0.3-0.7 \%, \mathrm{I}^{2}=0 \%$ ); there was no difference in surgery due to AEs between the ESD and the EMR group. 


\section{Study or subgroup}

EMR

Moss A, 2015

Urban O, 2008

Belle S, 2012

Yoshikane H, 1999

Tanaka, 2001

Tamura S, 2004

Su MY, 2008

Hurlstone DP, 2004

Binmoller KF, 2015

Terasaki, 2011 (EMR)

EMR subgroup

$\mathrm{Q}=90,90, P=0,00$, $r^{2}=90 \%$

ESD

Ritsuno H, 2014

Uraoka T, 2010

Niimi K, 2010

Nishiyama H, 2010

Sakamoto T, 2014

Makino T, 2010

Bae JH, 2016

Yoon JY, 2012

Xu MD, 2013

Cong Z], 2015

Zhou PH, 2009

Tang XW, 2016

Hulagu S, 2013

Berr F, 2014

Hurlstone DP, 2007

Probst A, 2012

Repici A, 2013

Terasaki, 2011 (ESD)

ESD subgroup

$\mathrm{Q}=222,71, P=0,00$, $r^{2}=92 \%$

Overall

$\mathrm{Q}=337,78, P=0,00$, $r^{2}=92 \%$

d
Submucosal invasion by technique

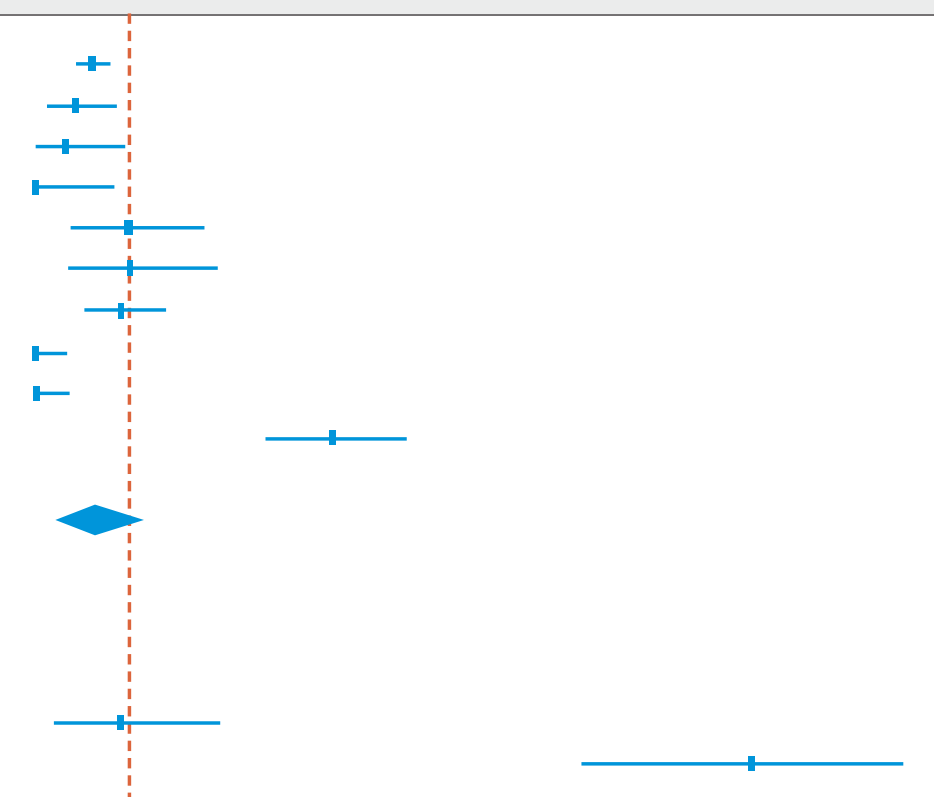

Prev $(95 \% \mathrm{Cl}) \quad \%$ Weight

$0,053(0,038,0,070) \quad 4,0$

$0,037(0,010,0,076) \quad 3,8$

$0,029(0,000,0,084) \quad 3,6$

$0,000(0,000,0,074) \quad 2,9$

$0,086(0,033,0,159) \quad 3,6$

$0,090(0,031,0,172) \quad 3,6$

$0,080(0,046,0,123) \quad 3,9$

$0,000(0,000,0,029) \quad 3,5$

$0,000(0,000,0,032) \quad 3,4$

$0,281(0,217,0,349) \quad 3,9$

$0,056(0,020,0,102) \quad 36,1$

$0,080(0,018,0,174) \quad 3,4$

$0,676(0,515,0,818) \quad 3,2$

$0,143(0,102,0,190) \quad 3,9$

$0,069(0,037,0,108) \quad 3,9$

$0,158(0,102,0,224) \quad 3,8$

$0,155(0,072,0,261) \quad 3,5$

$0,072(0,036,0,119) \quad 3,8$

$0,277(0,194,0,369) \quad 3,7$

$0,080(0,040,0,132) \quad 3,8$

$0,073(0,039,0,117) \quad 3,9$

$0,043(0,006,0,107) \quad 3,6$

$0,000(0,000,0,047) \quad 3,2$

$0,000(0,000,0,039) \quad 3,3$

$0,000(0,000,0,044) \quad 3,3$

$0,000(0,000,0,061) \quad 3,0$

$0,081(0,028,0,156) \quad 3,6$

$0,050(0,001,0,145) \quad 3,3$

$0,539(0,435,0,642) \quad 3,7$

$0,110(0,059,0,170) \quad 63,9$

$0,088(0,055,0,128) \quad 100,0$

- Fig. 2d Rate of curative resection according to technique. 
Study or subgroup

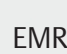

Moss A, 2015

Conio M, 2010

Fasoulas K, 2012

Urban O, 2008

Yoshikane H, 1999

Uraoka T, 2005

Tanaka, 2001

Tamura S, 2004

Huang Y, 2009

Hurlstone DP, 2004

Arebi N, 2007

Binmoller K, 2015

Terasaki, (EMR), 2011

Tajika M (EMR), 2011

EMR subgroup

$\mathrm{Q}=58,39, P=0,00$,

$\mathrm{I}^{2}=78 \%$

ESD

Ritsuno H, 2014

Nishiyama H, 2010

Makino T, 2015

Bae JH, 2015

Jung DH, 2015

Xu MD, 2013

Cong Z], 2015

Zhou PH, 2009

Tang XW, 2016

Hulagu S, 2013

Berr F, 2014

Probst A, 2012

Repici A, 2013

Terasaki M (ESD), 2011

Tajika M (ESD), 2011

ESD subgroup

$\mathrm{Q}=43,73, P=0,00$, $\mathrm{I}^{2}=68 \%$

Overall

$\mathrm{Q}=296,82, P=0,00$, $P^{2}=91 \%$

e
Recurrence by technique

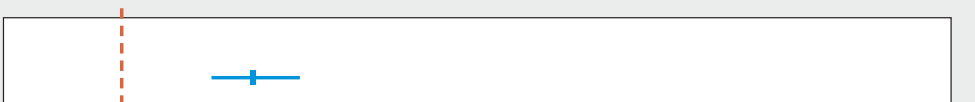

Prev $(95 \% \mathrm{Cl}) \quad$ \% Weight

$0,139(0,112,0,168) \quad 3,9$

$0,024(0,003,0,060) \quad 3,7$

$0,273(0,150,0,415) \quad 3,2$

$0,136(0,083,0,201) \quad 3,7$

$0,045(0,000,0,185) \quad 2,7$

$0,104(0,063,0,153) \quad 3,8$

$0,077(0,026,0,148) \quad 3,5$

$0,104(0,041,0,191) \quad 3,5$

$0,139(0,071,0,225) \quad 3,5$

$0,172(0,085,0,282) \quad 3,4$

$0,409(0,267,0,559) \quad 6,2$

$0,047(0,001,0,135) \quad 3,2$

$0,080(0,044,0,125) \quad 3,8$

$0,171(0,062,0,317) \quad 3,1$

$0,126(0,091,0,166) \quad 48,3$

$0,000(0,000,0,038) \quad 3,2$

$0,000(0,000,0,008) \quad 3,8$

$0,000(0,000,0,030) \quad 3,4$

$0,000(0,000,0,011) \quad 3,7$

$0,000(0,000,0,011) \quad 3,8$

$0,008(0,000,0,036) \quad 3,7$

$0,077(0,038,0,128) \quad 3,7$

$0,000(0,000,0,023) \quad 3,5$

$0,065(0,001,0,185) \quad 3,0$

$0,047(0,001,0,135) \quad 3,2$

$0,061(0,001,0,174) \quad 3,0$

$0,000(0,000,0,025) \quad 3,5$

$0,026(0,000,0,110) \quad 3,1$

$0,000(0,000,0,019) \quad 3,6$

$0,000(0,000,0,024) \quad 3,5$

$0,011(0,003,0,025) \quad 51,7$

$0,055(0,030,0,086) \quad 100,0$

- Fig. 2e Submucosal invasion by technique. 


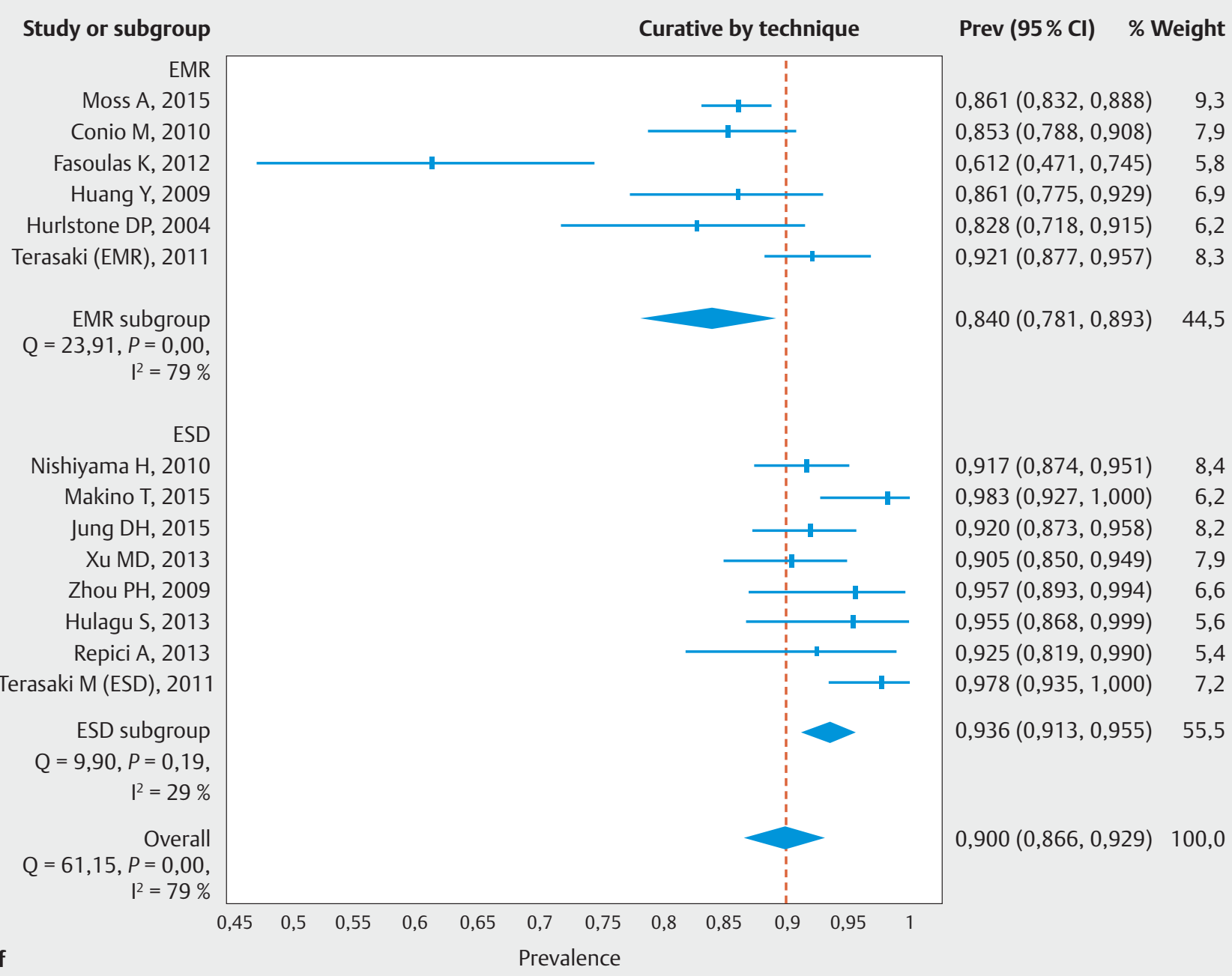

Fig. 2 f Recurrence rate by technique.

- 23 studies involving 2257 patients reported eight surgeries due to recurrences detected during follow up (pooled rate was $0.5 \%, 95 \% \mathrm{Cl} 0.2-0.8 \%, \mathrm{I}^{2}=0 \%$ ) ( $\left.\mathbf{F i g} .4 \mathbf{b}\right)$. There was no significant difference between the two techniques.

- 21 studies involving 2799 lesions reported 125 surgeries due to incomplete/non-curative resection (pooled rate was 4.3\%, $95 \% \mathrm{Cl} 3.3-5.5 \%, \mathrm{I}^{2}=44 \%$ ). No significant difference between EMR and ESD was found (pooled rate EMR was 3.9\%, $95 \% \mathrm{Cl} 2.5-5.5 \%, \mathrm{I}^{2}=55 \%$ vs. pooled rate ESD was $4.6 \%$, $95 \% \mathrm{Cl} 3.0-6.3 \%, \mathrm{I}^{2}=30 \%$ ) ( Fig. $4 \mathrm{c}$ ).

\section{Publication bias}

Visual inspection of the funnel plot and doi plot analysis (LFK index 0.14 - absence of asymmetry) suggests the absence of publication bias for the primary endpoint (curative resection).

\section{Discussion}

According to our analysis, both EMR and ESD were effective and safe with a low risk of procedure-related morbidity and rare mortality. Cure from the primary intervention was more fre- quently achieved with ESD (93.6\% vs. $84 \%$ for EMR) with higher recurrence among patients submitted to EMR (12.6\% vs. $1.1 \%$ for ESD) but the endoscopic treatment of recurrence was highly effective $(87.7 \%)$. We found no difference in surgery between both techniques due to incomplete endoscopic/histologic resection or recurrence.

The rate of AEs was low and most complications could be managed endoscopically, as shown by a surgery rate for AEs of $0.3 \%$. Clearly both techniques are very safe. Risk of perforation was significantly higher for ESD (5.9\% vs. $1.2 \%$ for EMR) and risk of bleeding was statistically greater with EMR (9.6\% vs. $2.8 \%$ for ESD), but major bleeding and delayed bleeding rates were similar for both techniques.

In this meta-analysis, we exclusively included LSTs according to the accepted definition of flat laterally spreading lesions > than $10 \mathrm{~mm}$. These lesions often cannot be reliably excised enbloc by conventional snare polypectomy, especially if larger than $20 \mathrm{~mm}$. In this study, we have examined the interface between the two available therapeutic techniques of EMR and ESD. This study evaluates outcomes in a defined, discrete and 


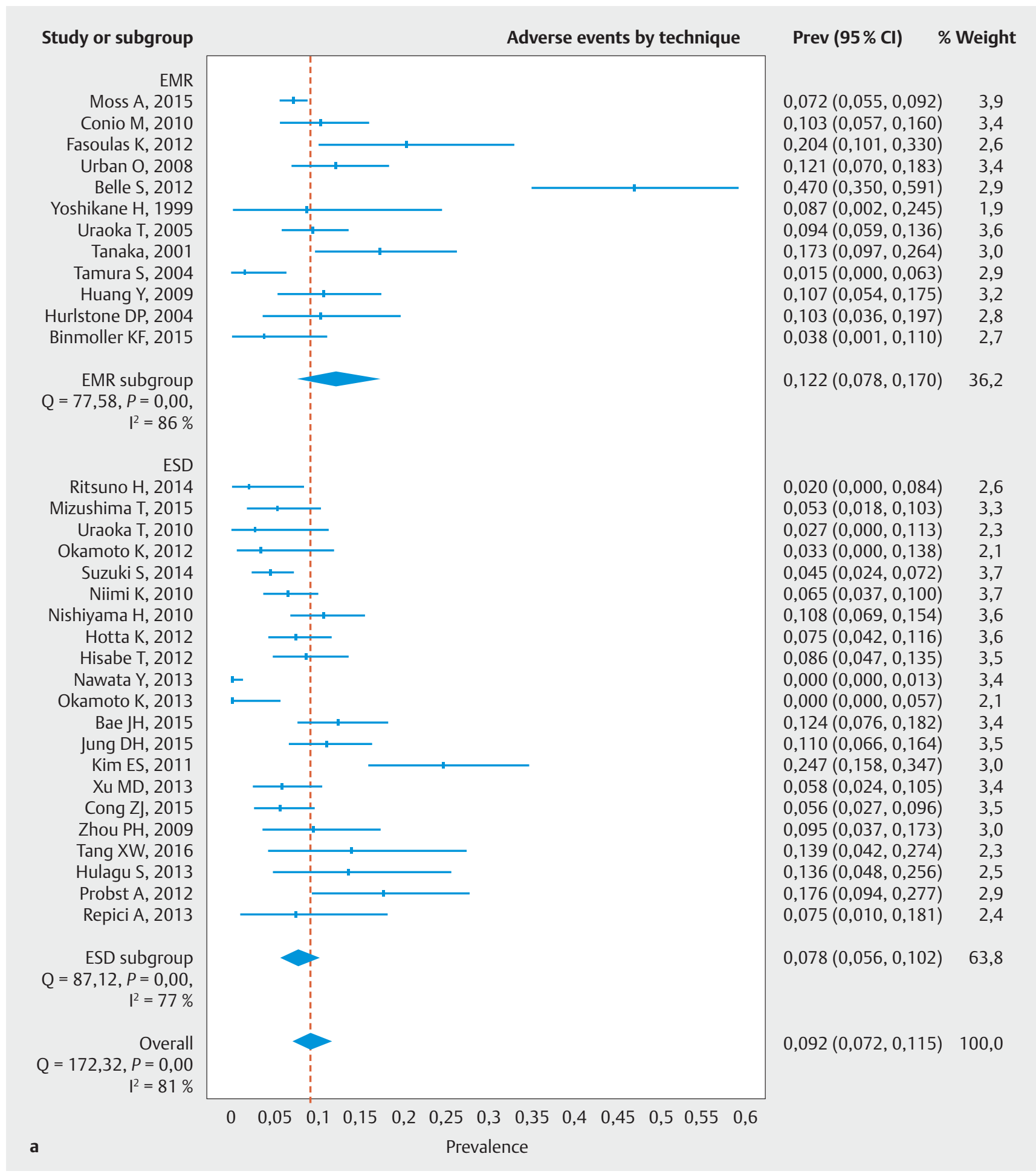

- Fig. 3a Adverse events. Overall adverse events by technique.

well characterized subgroup of large colorectal neoplasms and is substantially different from previous work [7, 28, 29].

Hassan et al. assessed efficacy and safety of endoscopic resection of large colorectal lesions (>20 mm) [7]. Broadly classified as sessile, pedunculated or non-polypoid, in this study, all types of tissue resection techniques including conventional po- lypectomy (26\%) were included. Consequently, there is relative data heterogeneity and the results are thus hard to interpret. Detailed morphological features are not described and thus the influence of morphology outcomes was not evaluated. Paris classification and surface morphology (granular/non-granular) were not assessed. Endoscopic tissue resection has continuous- 
Study or subgroup

\section{EMR}

Moss A, 2015

Conio M, 2010

Fasoulas K, 2012

Urban O, 2008

Belle S, 2012

Yoshikane H, 1999

Uraoka T, 2005

Tanaka S, 2001

Huang Y, 2009

Hurlstone DP, 2004

Arebi N, 2007

Binmoller KF, 2015

Terasaki (EMR), 2011

EMR subgroup

$\mathrm{Q}=26,89, P=0,01$. $P^{2}=55 \%$

ESD

Ritsuno H, 2014

Mizushima T, 2015

Uraoka T, 2010

Okamoto K, 2012

Niimi K, 2010

Nishiyama H, 2010

Hotta K, 2012

Hisabe T, 2012

Sakamoto T, 2014

Nawata Y, 2014

Makino T, 2015

Okamoto K, 2013

Bae JH, 2015

Lee EJ, 2011

Jung DH, 2015

Yoon JY, 2012

Kim ES, 2011

Xu MD, 2013

Cong ZJ, 2015

Zhou PH, 2009

Tang XW, 2016

Hulagu S, 2013

Berr F, 2014

Probst A, 2012

Teraski (ESD), 2011

ESD subgroup

$\mathrm{Q}=93,96, P=0,00$,

$r^{2}=74 \%$

Overall

$\mathrm{Q}=227,83, P=0,00$ $1^{2}=84 \%$

b
Perforation by technique

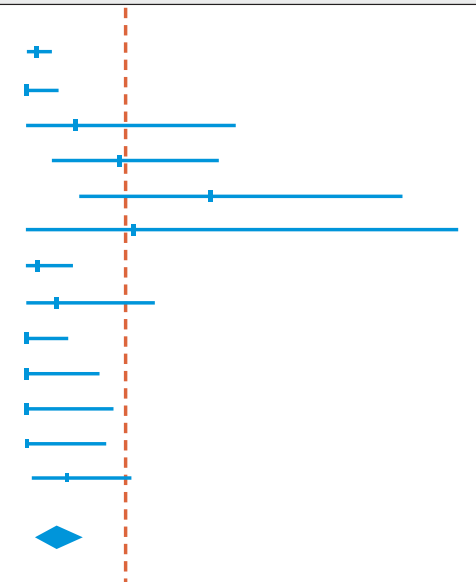

!
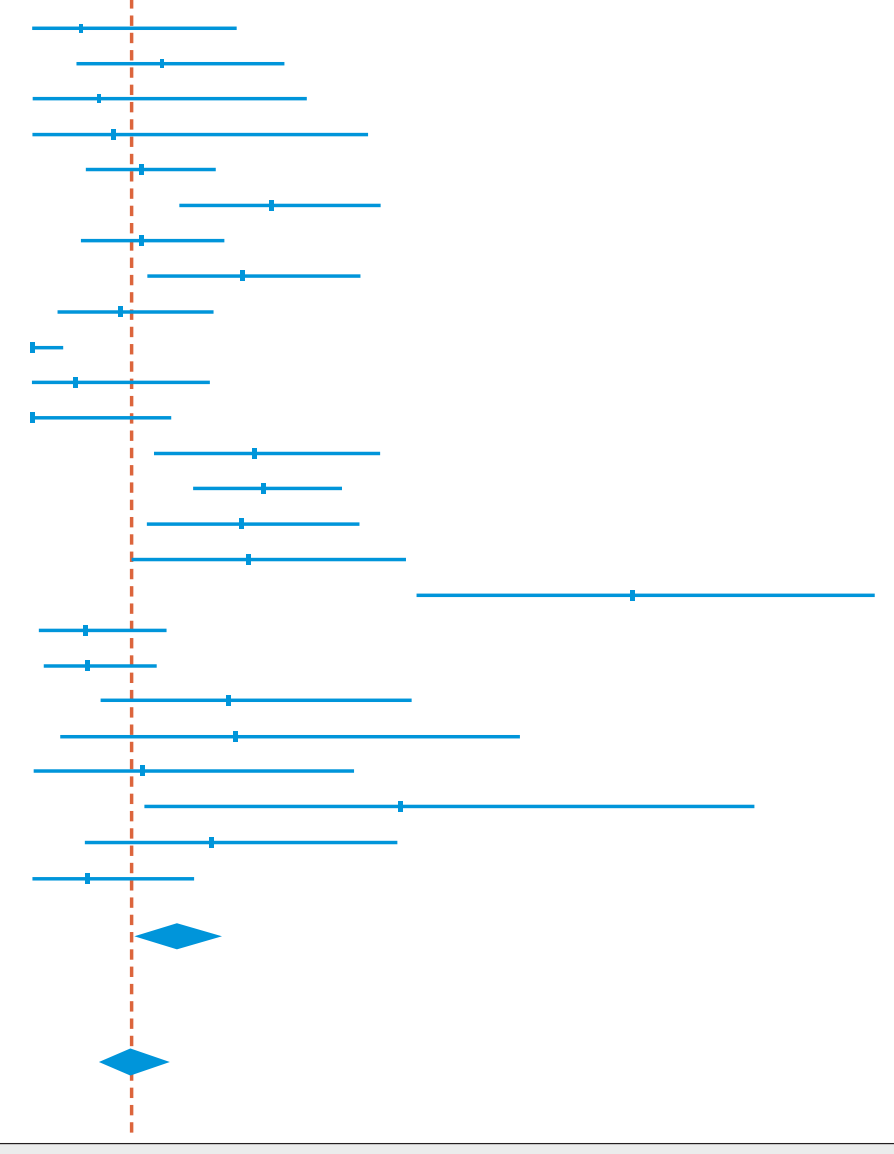

0

$$
0,05
$$

$$
0,1
$$

0,15

$$
0,2
$$

0,25

0,3

Prevalence

\section{Prev (95\% Cl) \% Weight}

$0,004(0,000,0,010) \quad 3,3$

$0,000(0,000,0,013) \quad 2,9$

$0,020(0,000,0,086) \quad 2,3$

$0,038(0,011,0,078) \quad 2,9$

$0,076(0,022,0,154) \quad 2,5$

$0,043(0,000,0,178) \quad 1,7$

$0,004(0,000,0,019) \quad 3,1$

$0,012(0,000,0,052) \quad 2,6$

$0,000(0,000,0,017) \quad 2,8$

$0,000(0,000,0,029) \quad 2,4$

$0,000(0,000,0,036) \quad 2,3$

$0,000(0,000,0,032) \quad 2,4$

$0,017(0,002,0,042) \quad 3,0$

$0,012(0,005,0,023) \quad 34,1$

$0,020(0,000,0,084) \quad 2,3$

$0,053(0,018,0,103) \quad 2,8$

$0,027(0,000,0,113) \quad 2,1$

$0,033(0,000,0,138) \quad 1,9$

$0,045(0,022,0,075) \quad 3,1$

$0,098(0,061,0,143) \quad 3,1$

$0,045(0,020,0,079) \quad 3,0$

$0,086(0,047,0,135) \quad 3,0$

$0,036(0,010,0,075) \quad 2,9$

$0,000(0,000,0,013) \quad 2,9$

$0,017(0,000,0,073) \quad 2,4$

$0,000(0,000,0,057) \quad 1,9$

$0,092(0,050,0,143) \quad 2,9$

$0,095(0,067,0,128) \quad 3,2$

$0,086(0,047,0,134) \quad 3,0$

$0,089(0,040,0,154) \quad 2,8$

$0,247(0,158,0,347) \quad 2,6$

$0,022(0,003,0,055) \quad 2,9$

$0,023(0,005,0,051) \quad 3,0$

$0,081(0,028,0,156) \quad 2,6$

$0,083(0,011,0,201) \quad 2,1$

$0,045(0,001,0,132) \quad 2,2$

$0,152(0,046,0,297) \quad 2,0$

$0,074(0,021,0,150) \quad 2,5$

$0,022(0,000,0,067) \quad 2,7$

$0,059(0,043,0,079) \quad 65,9$

$0,041(0,027,0,056) \quad 100,0$

Fig.3b Adverse events. Perforation by technique. 
Study or subgroup

EMR
Burgess NG, 2014 Conio M, 2010

Fasoulas K, 2012 Urban O, 2008 Belle S, 2012

Yoshikane H, 1999 Uraoka T, 2005 Tanaka, 2001 Tamura S, 2004 Huang Y, 2009 Hurlstone DP, 2004 Binmoller KF, 2015 Terasaki (EMR), 2011

EMR subgroup $\mathrm{Q}=69,37, P=0,00$, $\mathrm{I}^{2}=83 \%$

\section{ESD}

Ritsuno H, 2014 Uraoka T, 2010

Okamoto K, 2012 Suzuki S, 2014 Niimi K, 2010

Nishiyama H, 2010 Hotta K, 2012

Nawata Y, 2014

Okamoto K, 2013 Bae JH, 2015 Jung DH, 2015 Xu MD, 2013 Cong ZJ, 2015 Zhou PH, 2009 Tang XW, 2016 Hulagu S, 2013 Probst A, 2012 Repici A, 2013 Teraski (ESD), 2011

ESD subgroup $Q=39,80, P=0,00$, $\mathrm{I}^{2}=55 \%$

$$
\text { Overall }
$$

$\mathrm{Q}=199,64, P=0,00$ $\mathrm{I}^{2}=84 \%$

c
Bleeding by technique

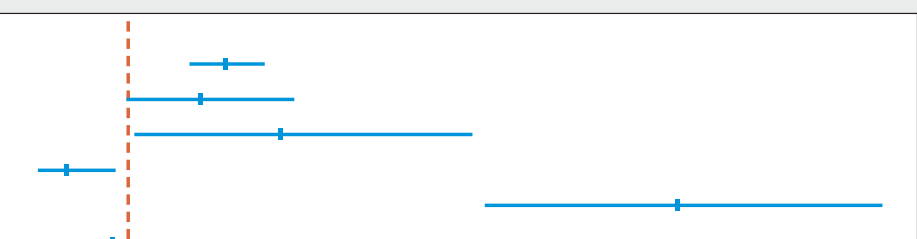

$0,111(0,090,0,134)$

$0,096(0,051,0,151)$

$0,143(0,057,0,257)$

$0,015(0,000,0,045)$

$0,379(0,265,0,500)$

$0,043(0,000,0,178)$

$0,090(0,055,0,131)$

$0,160(0,088,0,249)$

$0,015(0,000,0,063)$

$0,107(0,054,0,175)$

$0,103(0,036,0,197)$

$0,019(0,000,0,079)$

$0,084(0,047,0,130)$

$0,097(0,063,0,134)$

$0,000(0,000,0,034)$

$0,000(0,000,0,046)$

$0,000(0,000,0,057)$

$0,045(0,024,0,072)$

$0,020(0,006,0,043)$

$0,010(0,000,0,029)$

$0,030(0,010,0,059)$

$0,000(0,000,0,013)$

$0,000(0,000,0,057)$

$0,033(0,009,0,068)$

$0,025(0,005,0,055)$

$0,036(0,010,0,076)$

$0,028(0,008,0,059)$

$0,014(0,000,0,057)$

$0,028(0,000,0,116)$

$0,091(0,021,0,197)$

$0,088(0,030,0,169)$

$0,050(0,001,0,145)$

$0,115(0,045,0,209)$

$0,029(0,019,0,042)$

58,9

$0,053(0,036,0,073) \quad 100,0$

- Fig.3c Adverse events. Bleeding rate by technique.

ly developed and improved over time, particularly in the last 10 years. Hassan et al. included eight studies before 2000 which may have substantially influenced the outcomes of the analysis [7]. The main outcome of this study was the rate of subsequent surgery for all reasons. The surgery rate was $8.3 \%$, among these $0.5 \%$ due to AEs and $7.8 \%$ due to non-curative resections. In our study, of LSTs excised by EMR or ESD, the rate of post-endoscopic resection surgery was $2.7 \%$. In pooled rate analysis of our data, surgery due to non-curative endoscopic resection,
AEs and recurrence were $4.2 \%, 0.5 \%$ and $0.5 \%$ respectively. Overall AEs were $9.2 \%$, perforations accounted for $4.1 \%$ and bleeding was $5.3 \%$.

Overall the recurrence rate in our study was $5.5 \%$ which is lower than reported in other studies. Hassan et al. reported an overall recurrence rate of $13.8 \%$, while the recurrence rate post-EMR versus post-ESD in both studies was $12.7 \%$ vs. $1.1 \%$ and $15 \%$ vs. $1 \%$, respectively [7]. Belderbos et al. evaluated 33 EMR (>10 mm) studies for recurrence rate [28]. The overall re- 
Study or subgroup

EMR

Moss A, 2015

Conio M, 2010

Fasoulas K, 2012

Urban O, 2008

Belle S, 2012

Uraoka T, 2005

Tanaka, 2001

Tamura S, 2004

Su MY, 2008

Huang Y, 2009

Hurlstone DP, 2004

Arebi N, 2007

Binmoller KF, 2015

Terasaki (EMR), 2011

Hurlstone DP (EMR), 2006

EMR subgroup

$\mathrm{Q}=41,42, P=0,00$, $P^{2}=66 \%$

ESD

Ritsuno H, 2014

Uraoka T, 2010

Suzuki S, 2014

Niimi K, 2010

Nishiyama H, 2010

Hotta K, 2012

Makino T, 2015

Okamoto K, 2013

Jung DH, 2015

Yoon JY, 2012

Kim ES, 2011

Xu MD, 2013

Cong ZJ, 2015

Zhou PH, 2009

Tang XW, 2016

Hulagu S, 2013

Berr F, 2014

Hurlstone DP, 2007

Probst A, 2012

Repici A, 2013

Terasaki (ESD), 2011

ESD subgroup

$\mathrm{Q}=71,97, P=0,00$, $P^{2}=72 \%$

Overall

$\mathrm{Q}=130,33, P=0,00$

$$
r^{2}=73 \%
$$

a
Surgery overall by technique
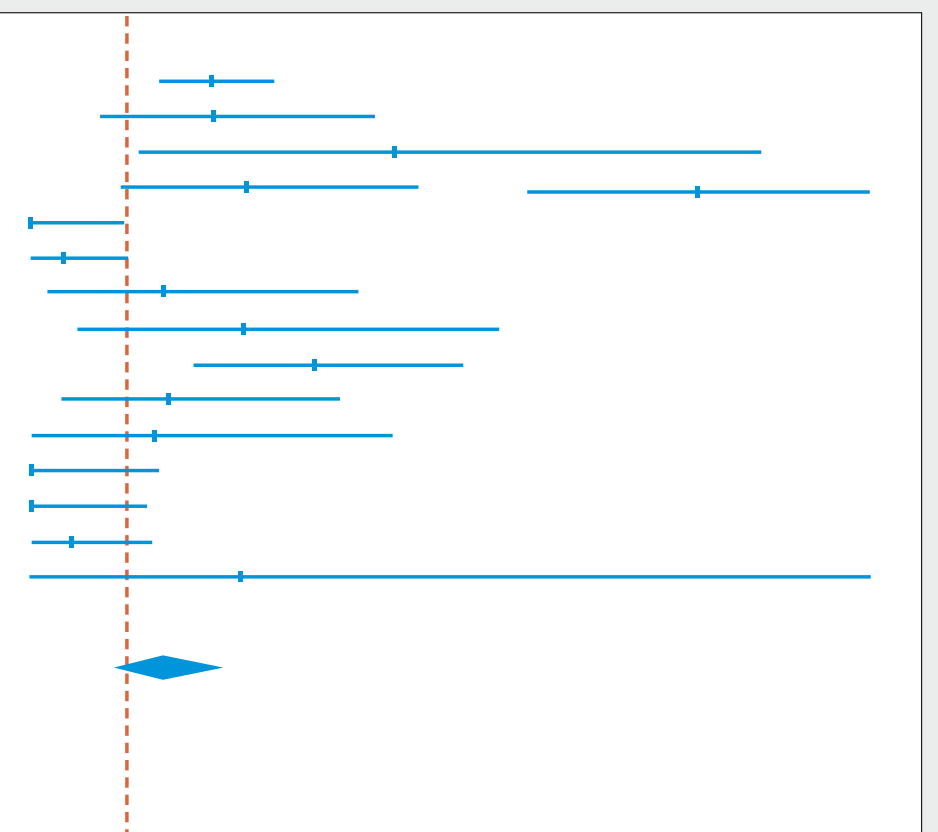

$0,000(0,000,0,034) \quad 2,3$

$0,000(0,000,0,046) \quad 2,0$

$0,000(0,000,0,006) \quad 3,7$

$0,008(0,000,0,024) \quad 3,7$

$0,025(0,007,0,051) \quad 3,5$

$0,005(0,000,0,021) \quad 3,5$

$0,000(0,000,0,030) \quad 2,5$

$0,000(0,000,0,057) \quad 1,8$

$0,067(0,033,0,112) \quad 3,4$

$0,000(0,000,0,017) \quad 3,0$

$0,000(0,000,0,021) \quad 2,8$

$0,073(0,035,0,123) \quad 3,3$

$0,062(0,031,0,103) \quad 3,5$

$0,014(0,000,0,057) \quad 2,7$

$0,028(0,000,0,116) \quad 2,0$

$0,023(0,000,0,095) \quad 2,2$

$0,030(0,000,0,126) \quad 1,9$

$0,000(0,000,0,061) \quad 1,7$

$0,000(0,000,0,025) \quad 2,6$

$0,050(0,001,0,145) \quad 2,1$

$0,077(0,030,0,142) \quad 2,9$

$0,020(0,010,0,034) \quad 57,1$

$0,027(0,018,0,038) \quad 100,0$

- Fig.4a Follow-up and surgery. Overall surgery rate by technique.

currence rate was as high as $15 \%$, with $3 \%$ for en-bloc resections and $22 \%$ for piecemeal resections. Treatment of recurrence was successful in $91.4 \%$ of the lesions, after a median of 1.2 endoscopic retreatments. Piecemeal resection was the only risk factor that was clearly associated with recurrence in multivariable analysis [28].
In ESD treatment, Puli and Hassan both reported en-bloc rates of $85 \%$ and $50 \%$, respectively $[7,29]$. These rates are lower than our data ( $93.7 \%$ en-bloc). In our analysis, according to our predefined and more stringent criteria most of the ESD studies were from the east. 
Study or subgroup

EMR

Conio M, 2010

Fasoulas K, 2012

Urban O, 2008

Uraoka T, 2005

Tanaka, 2001

Tamura S, 2004

Huang Y, 2009

Hurlstone DP, 2004

Binmoller KF, 2015

Terasaki (EMR), 2011

Hurlstone DP (EMR),

2006

EMR subgroup

$\mathrm{Q}=10,58, P=0,39$,

$1^{2}=6 \%$

ESD

Niimi K, 2010

Nishiyama H, 2010

Makino T, 2015

Xu MD, 2013

Cong ZJ, 2015

Zhou PH, 2009

Tang XW, 2016

Berr F, 2014

Probst A, 2012

Repici A, 2013

Terasaki (ESD), 2011

ESD subgroup

$\mathrm{Q}=3,88, P=0,95$, $\mathrm{I}^{2}=0 \%$ Overall

$\mathrm{Q}=14,51, P=0,85$

$$
1^{2}=0 \%
$$

b
Surgery due to recurrence by technique

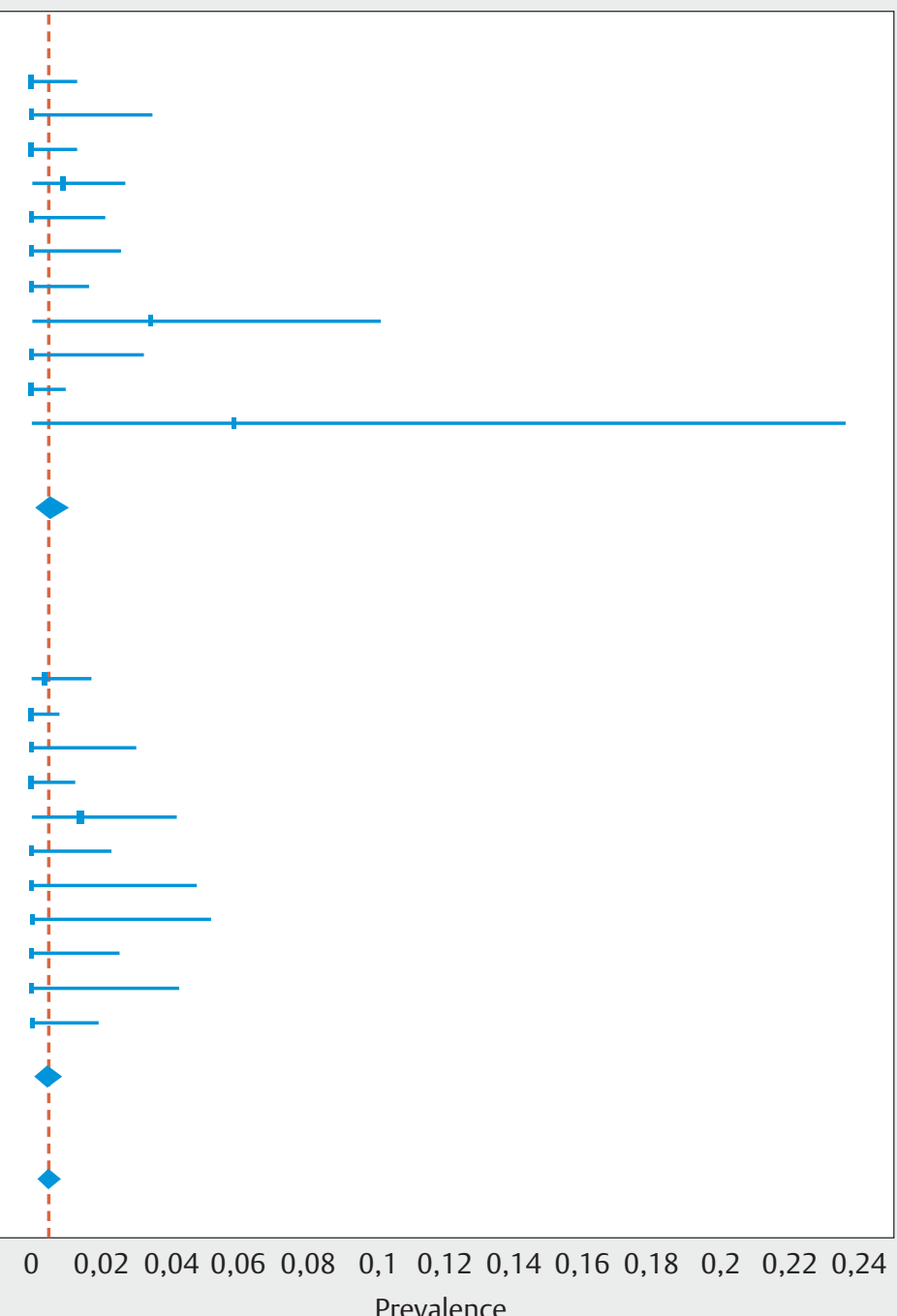

$\operatorname{Prev}(95 \% \mathrm{Cl})$

\% Weight

$0,000(0,000,0,013)$

$0,000(0,000,0,035) \quad 2,2$

$0,000(0,000,0,013) \quad 5,9$

$0,009(0,000,0,027) \quad 10,0$

$0,000(0,000,0,021) \quad 3,7$

$0,000(0,000,0,026) \quad 3,0$

$0,000(0,000,0,017) \quad 4,6$

$0,034(0,001,0,101) \quad 2,6$

$0,000(0,000,0,032) \quad 2,4$

$0,000(0,000,0,010) \quad 7,9$

$0,059(0,000,0,236) \quad 0,8$

$0,005(0,001,0,010) \quad 49,3$

$0,004(0,000,0,017) \quad 11,0$

$0,000(0,000,0,008) \quad 9,2$

$0,000(0,000,0,030) \quad 2,6$

$0,000(0,000,0,013) \quad 6,2$

$0,014(0,000,0,042) \quad 6,4$

$0,000(0,000,0,023) \quad 3,3$

$0,000(0,000,0,047) \quad 1,6$

$0,000(0,000,0,052) \quad 1,5$

$0,000(0,000,0,025) \quad 3,1$

$0,000(0,000,0,043) \quad 1,8$

$0,000(0,000,0,019) \quad 4,0$

$0,004(0,001,0,009) \quad 50,7$

$0,005(0,002,0,008) \quad 100,0$

Fig.4b Follow-up and surgery. Rate of surgery due to recurrence by technique.

Mortality related to endoscopic procedures was similar ( $0.08 \%$ in Hassan C. et al. vs. $0.10 \%$ in our data) [7].

In this meta-analysis, we included mainly observational cohort studies and case-control studies, most of them either single-center or retrospective. However, to mitigate the risk of bias, we used the Newcastle-Ottawa Scale for assessing the quality of nonrandomized studies.

\section{Limitations}

Our search did not retrieve any results on minimally invasive transanal surgery (transanal endoscopic microsurgery), mostly because in the studies involving these techniques a morphologic classification was not applied. It would be advisable to apply this classification in future studies evaluating these techniques.

One of the major limitations of our work is the heterogeneous classification of lesions applied in the different papers. Many studies on the endoscopic treatment of large (>10 mm)
Paris 0 -Ila lesions (as well as 0 -Ila $+\mathrm{c}$ or 0 -IIa + Is) were excluded because the denomination LST was not present. Most, if not all these lesions probably correspond to LST. Several studies that included LST along with other polypoid and non-polypoid lesions that didn't make a subanalysis of LST subgroup were also excluded. The other major limitation refers to the fact that most of the studies are either single-center or retrospective.

Data are scarce to compare the outcomes for the different LST subtypes (LST-GH, LST-GM, LST-NGF and LST-NGPD). For many non-Japanese studies, chromoendoscopy is not routinely applied, hence this may affect the accuracy of the morphological diagnosis of LST (especially LST-NG-PD) and evaluation of residual neoplasm in resection margin. The histological characteristics were usually not analyzed and they can play a major role in the outcomes, as more advanced histological lesions are related with lower curative resection. 
Study or subgroup Surgery due to incomplete/non-curative resection by technique

MMR

Conio M, 2010

Fasoulas K, 2012

Urban O, 2008

Tanaka, 2001

Tamura S, 2004

Su MY, 2008

Huang Y, 2009

Hurlstone DP, 2004

Binmoller KF, 2015

Terasaki (EMR), 2011

EMR subgroup

$\mathrm{Q}=23,40, P=0,01$, $P^{2}=57 \%$

ESD

Nishiyama H, 2010

Jung $\mathrm{DH}, 2015$

Xu MD, 2013

Cong ZJ, 2015

Zhou PH, 2009

Tang XW, 2016

Hulagu S, 2013

Hurlstone DP, 2007

Repici A, 2013

Terasaki (ESD), 2011

ESD subgroup

$\mathrm{Q}=12,87, P=0,17$,

$P^{2}=30 \%$

Overall

$\mathrm{Q}=36,38, P=0,01$ $P^{2}=45 \%$

C

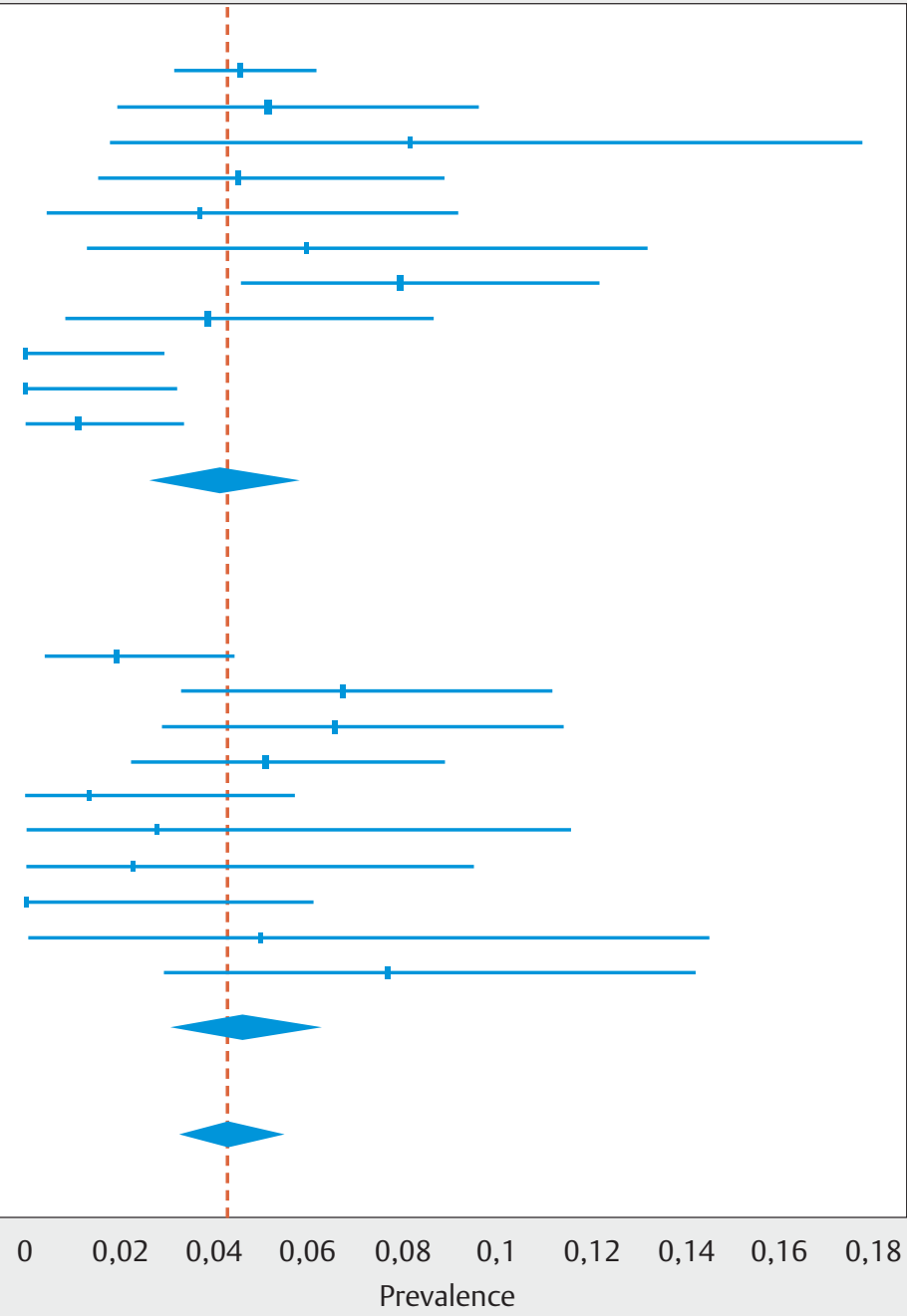

\section{Prev $(95 \% \mathrm{Cl}) \quad$ \% Weight}

$0,046(0,032,0,062) \quad 10,0$

$0,051(0,020,0,096) \quad 5,7$

$0,082(0,018,0,178) \quad 2,9$

$0,045(0,015,0,089) \quad 5,6$

$0,037(0,005,0,092) \quad 4,2$

$0,060(0,013,0,132) \quad 3,7$

$0,080(0,046,0,121) \quad 6,9$

$0,039(0,008,0,087) \quad 4,9$

$0,000(0,000,0,029) \quad 3,3$

$0,000(0,000,0,032) \quad 3,1$

$0,011(0,000,0,034) \quad 6,5$

$0,041(0,026,0,058) \quad 56,8$

$0,020(0,004,0,044) \quad 6,9$

$0,067(0,033,0,112) \quad 6,2$

$0,066(0,029,0,114) \quad 5,7$

$0,051(0,023,0,089) \quad 6,5$

$0,014(0,000,0,057) \quad 3,9$

$0,028(0,000,0,116) \quad 2,3$

$0,023(0,000,0,095) \quad 2,7$

$0,000(0,000,0,061) \quad 1,9$

$0,050(0,001,0,145) \quad 2,5$

$0,077(0,030,0,142) \quad 4,5$

$0,046(0,030,0,063) \quad 43,2$

$0,043(0,033,0,055) \quad 100,0$

Fig.4c Follow-up and surgery. Rate of surgery due to incomplete resection by technique.

The duration from endoscopic treatment to surveillance examination was heterogeneous between the studies and may have affected the rate of early recurrence.

\section{Conclusion}

A wide range of definitions was applied to describe LST, not always concordant. Therefore, it is of paramount importance to establish an unambiguous and consensus definition for these lesions.

Definitions are nearly unanimous in describing LST as flat or non-polypoid lesions that extend laterally (or horizontally, or superficially) and circumferentially, rather than vertically along the colonic wall [20,30-38].

Although some studies consider a minimum of $20 \mathrm{~mm}$ of diameter to fit in this classification $[39,40]$. Most of the authors include lesions beyond $10 \mathrm{~mm}$ in this group [4, 20, 30, 32, $34-$ 38,41-44]. Another contention appears when establishing the maximum allowed vertical growth. Most commonly lateral- ly spreading lesions within the fully inflated colon are described as lesions with height of less than half the diameter [45]. Bae JH et al. [15], defined LST as lesions with less than $2.5 \mathrm{~mm}$ in height.

Some authors make no distinction between sessile lesions and LST [46], while many other authors, despite making this distinction, analyze them in the same group of large sessile and laterally spreading lesions $[47,48]$. The difference between large sessile and laterally spreading tumors can actually be difficult and subjective. The Paris endoscopic classification of superficial neoplastic lesions of 2002 states that slightly elevated lesions are easily misclassified as sessile (polypoid subtype) at endoscopy. This distinction is more reliable on pathologic examination of an operative specimen, in which it is possible to compare the height of the lesion with the full thickness of the normal mucosa, although this also has limitations due to specimen shrinkage with fixation. 
When applying the Paris classification into the LST sub-classification, most authors include Ila, Ila + Is and Ila + Ilc lesions in this group $[5,24,49]$. Some studies also classify these lesions as IIb $[18,24]$ and Ila + IIb [19]. Berr F et al. classified LST-GH as Ila, LST-GM as Ila + Is, LST-NGF as Ila or IIb and LST-NGPD as Ila +c [24]. However, some authors have considered LST-NG as Ila and LST-G as Ila + Is lesions $[49,50]$.

Alternatively, some studies differentiate an LST group from a Paris II group (including Ila lesions), with both groups having large $>10 \mathrm{~mm}$ lesions [22, 51, 52].

In the Paris consensus of 2002 "lateral spreading type" lesions were included in type 0-Ila [3].

The authors suggest the following criteria to classify a lesion as LST:

1. Flat or non-polypoid lesions that extend laterally and circumferentially rather than vertically along the colonic wall, with a minimum diameter of $10 \mathrm{~mm}$.

2. Laterally spreading lesions shall be slightly elevated or at least have a real flat component (0-Ila). Pure sessile lesions (Paris 0-Is) shall not be classified as LST. To differentiate LST from sessile lesions the height of these lesions must be less than half of its diameter.

3. LST shall be classified into LST-G, which includes LST-GH (which corresponds to Paris 0-Ila lesions) and LST-GM (Paris 0 -Ila + Is lesions) and LST-NG, which includes LST-NGF (Paris $0-\| l a)$ and LST-NGPD (Paris $0-I I a+c)$.

\section{Competing interests}

None

\section{References}

[1] Kudo S, Lambert R, Allen Jl et al. Nonpolypoid neoplastic lesions of the colorectal mucosa. Gastrointest Endosc 2008; 68: S3-47

[2] Kudo S. Endoscopic mucosal resection of flat and depressed types of early colorectal cancer. Endoscopy 1993; 25: 455-61

[3] The Paris endoscopic classification of superficial neoplastic lesions: esophagus, stomach, and colon: November 30 to December 1, 2002. Gastrointest Endosc 2003; 58: S3-43

[4] Urban O, Vitek P, Fojtik P et al. Laterally spreading tumors - experience based on 138 consecutive cases. Hepatogastroenterology 2008; 55: $351-355$

[5] Probst A, Golger D, Anthuber M et al. Endoscopic submucosal dissection in large sessile lesions of the rectosigmoid: learning curve in a European center. Endoscopy 2012; 44: 660-667

[6] Pimentel-Nunes P, Dinis-Ribeiro M, Ponchon T et al. Endoscopic submucosal dissection: European Society of Gastrointestinal Endoscopy (ESGE) Guideline. Endoscopy 2015; 47: 829-854

[7] Hassan C, Repici A, Sharma P et al. Efficacy and safety of endoscopic resection of large colorectal polyps: a systematic review and meta-analysis. Gut 2016; 65: $806-820$

[8] Fujiya M, Tanaka K, Dokoshi T et al. Efficacy and adverse events of EMR and endoscopic submucosal dissection for the treatment of coIon neoplasms: a meta-analysis of studies comparing EMR and endoscopic submucosal dissection. Gastrointest Endosc 2015; 81: 583 595
[9] Wang S, Gao S, Yang W et al. Endoscopic submucosal dissection versus local excision for early rectal cancer: a systematic review and meta-analysis. Tech Coloproctol 2016; 20: 1-9

[10] Liberati A, Altman DG, Tetzlaff J et al. The PRISMA statement for reporting systematic reviews and meta-analyses of studies that evaluate healthcare interventions: explanation and elaboration. BMJ 2009; 339: b2700

[11] Niimi K, Fujishiro M, Kodashima S et al. Long-term outcomes of endoscopic submucosal dissection for colorectal epithelial neoplasms. Endoscopy 2010; 42: $723-729$

[12] Nishiyama $\mathrm{H}$, Isomoto $\mathrm{H}$, Yamaguchi $\mathrm{N}$ et al. Endoscopic submucosal dissection for laterally spreading tumours of the colorectum in 200 consecutive cases. Surg Endosc 2010; 24: 2881 - 2887

[13] Suzuki S, Chino A, Kishihara T et al. Risk factors for bleeding after endoscopic submucosal dissection of colorectal neoplasms. World ] Gastroenterol 2014; 20: 1839-1845

[14] Uraoka T, Fujii T, Saito Y et al. Effectiveness of glycerol as a submucosal injection for EMR. Gastrointest Endosc 2005; 61: 736 - 740

[15] Bae JH, Yang DH, Lee JY et al. Clinical outcomes of endoscopic submucosal dissection for large colorectal neoplasms: a comparison of protruding and laterally spreading tumors. Surg Endosc 2016; 30: $1619-1628$

[16] Conio M, Blanchi S, Filiberti R. Cap-assisted endoscopic mucosal resection of large polyps involving the ileocecal valve. Endoscopy 2010; 42: $677-680$

[17] Yoshikane H, Hidano H, Sakakibara A et al. Endoscopic resection of laterally spreading tumours of the large intestine using a distal attachment. Endoscopy 1999; 31: 426-430

[18] Fasoulas K, Lazaraki G, Chatzimavroudis G et al. Endoscopic mucosal resection of giant laterally spreading tumors with submucosal injection of hydroxyethyl starch: comparative study with normal saline solution. Surg Laparosc Endosc Percutan Tech 2012; 22: 272-278

[19] Binmoeller KF, Hamerski CM, Shah JN et al. Attempted underwater en bloc resection for large $(2-4 \mathrm{~cm})$ colorectal laterally spreading tumors (with video). Gastrointest Endosc 2015; 81: 713- 718

[20] Hulagu S, Senturk O, Korkmaz U et al. Endoscopic submucosal dissection for colorectal laterally spreading tumors. Turk J Gastroenterol 2013; 24: $532-540$

[21] lizuka H, Okamura S, Onozato Y et a. Endoscopic submucosal dissection for colorectal tumors. Gastroenterol Clin Biol 2009; 33: 1004 1011

[22] Hurlstone DP, Atkinson R, Sanders DS et al. Achieving R0 resection in the colorectum using endoscopic submucosal dissection. $\mathrm{Br}$ J Surg 2007; 94: 1536 - 1542

[23] Kim ES, Cho KB, Park KS et al. Factors predictive of perforation during endoscopic submucosal dissection for the treatment of colorectal tumors. Endoscopy 2011; 43: 573-578

[24] Berr F, Wagner A, Kiesslich T et al. Untutored learning curve to establish endoscopic submucosal dissection on competence level. Digestion 2014; 89: $184-193$

[25] Belle S, Collet PH, Szyrach M et al. Selective tissue elevation by pressure for endoscopic mucosal resection of colorectal adenoma: first clinical trial. Surg Endosc 2012; 26: 343-349

[26] Kim HG, Thosani N, Banerjee S et al. Underwater endoscopic mucosal resection for recurrences after previous piecemeal resection of colorectal polyps (with video). Gastrointest Endosc 2014; 80: 1094-1102

[27] Arebi N, Swain D, Suzuki NI et al. Endoscopic mucosal resection of 161 cases of large sessile or flat colorectal polyps. Scand J Gastroenterol 2007; 42: 859-866

[28] Belderbos TD, Leenders M, Moons LM et al. Local recurrence after endoscopic mucosal resection of nonpedunculated colorectal lesions: systematic review and meta-analysis. Endoscopy 2014; 46: 388-402 
[29] Puli SR, Kakugawa Y, Saito Y et al. Successful complete cure en-bloc resection of large nonpedunculated colonic polyps by endoscopic submucosal dissection: a meta-analysis and systematic review. Ann Surg Oncol 2009; 16: 2147-2151

[30] Tang XW, Ren YT, Zhou JQ et al. Endoscopic submucosal dissection for laterally spreading tumors in the rectum $>1=40 \mathrm{~mm}$. Tech Coloproctol 2016; 20: 437 - 443

[31] Youk EG, Sohn DK, Hong CW et al. Early Outcomes of Endoscopic Submucosal Dissection for Colorectal Neoplasms According to Clinical Indications. Dis Colon Rectum 2016; 59: 403 - 410

[32] Yamada M, Saito Y, Sakamoto T et al. Endoscopic predictors of deep submucosal invasion in colorectal laterally spreading tumors. Endoscopy 2016; 48: $456-464$

[33] Kobayashi N, Saito Y, Uraoka T et al. Treatment strategy for laterally spreading tumors in Japan: before and after the introduction of endoscopic submucosal dissection. J Gastroenterol Hepatol 2009; 24 : $1387-1392$

[34] Rotondano G, Bianco MA, Buffoli F. The Cooperative Italian FLIN Study Group: prevalence and clinico-pathological features of colorectal laterally spreading tumors. Endoscopy 2011; 43: 856-861

[35] Imai K, Hotta K, Yamaguchi Y et al. Should laterally spreading tumors granular type be resected en bloc in endoscopic resections? Surg Endosc 2014; 28: 2167-2173

[36] Cong Z], Hu LH, Ji JT et al. A long-term follow-up study on the prognosis of endoscopic submucosal dissection for colorectal laterally spreading tumors. Gastrointest Endosc 2016; 83: 800 - 807

[37] Horiuchi Y, Chino A, Matsuo Y et al. Diagnosis of laterally spreading tumors (LST) in the rectum and selection of treatment: characteristics of each of the subclassifications of LST in the rectum. Dig Endosc 2013; 25: $608-614$

[38] Huang Y, Liu S, Gong W et al. Clinicopathologic features and endoscopic mucosal resection of laterally spreading tumors: experience from China. Int J Colorectal Dis 2009; 24: 1441 - 1450

[39] Byeon JS, Yang DH, Kim KJ et al. Endoscopic submucosal dissection with or without snaring for colorectal neoplasms. Gastrointest Endosc 2011; 74: $1075-1083$

[40] Nakagoe T, Sawai T, Tsuji T et al. Minilaparotomy approach for the resection of laterally spreading tumors of the colon. Surg Today 2004; 34: $737-74$

[41] Xu MD, Wang XY, Li QL et al. Colorectal lateral spreading tumor subtypes: clinicopathology and outcome of endoscopic submucosal dissection. Int J Colorectal Dis 2013; 28: 63-72

[42] Jung D, Youn YH, Jahng J et al. Risk of electrocoagulation syndrome after endoscopic submucosal dissection in the colon and rectum. Endoscopy 2013; 45: 714-717

[43] Facciorusso A, Antonino M, Di Maso M et al. Non-polypoid colorectal neoplasms: Classification, therapy and follow-up. World J Gastroenterol 2015; 21: 5149-5157

[44] Tantau Al, Tantau MV, Serban A et al. Prevalence, histology, endoscopic treatment and long-term follow-up of large colonic polyps and laterally spreading tumors. The Romanian experience. J Gastrointestin Liver Dis 2008; 17: 419-425

[45] Cha JM, Lim KS, Lee SH et al. Clinical outcomes and risk factors of post-polypectomy coagulation syndrome: a multicenter, retrospective, case-control study. Endoscopy 2013; 45: 202 - 207

[46] Toyonaga T, Man-i M, Fujita T et al. Retrospective study of technical aspects and complications of endoscopic submucosal dissection for laterally spreading tumors of the colorectum. Endoscopy 2010; 42: $714-722$

[47] Metz AJ, Bourke M], Moss A et al. Factors that predict bleeding following endoscopic mucosal resection of large colonic lesions. Endoscopy 2011; 43: $506-511$
[48] Jayanna M, Burgess NG, Singh R et al. Cost Analysis of Endoscopic Mucosal Resection vs. Surgery for Large Laterally Spreading Colorectal Lesions. Clin Gastroenterol Hepatol 2016; 14: 271 - 278 e1-2

[49] Sakamoto T, Sato C, Makazu M et al. Short-term outcomes of colorectal endoscopic submucosal dissection performed by trainees. Digestion 2014; 89: 37-42

[50] Abe S, Sakamoto T, Takamaru $\mathrm{H}$ et al. Stenosis rates after endoscopic submucosal dissection of large rectal tumors involving greater than three quarters of the luminal circumference. Surg Endosc 2016; 30: $5459-5464$

[51] Hurlstone DP, Fu KI, Brown SR et al. EMR using dextrose solution versus sodium hyaluronate for colorectal Paris type I and 0-II lesions: a randomized endoscopist-blinded study. Endoscopy 2008; 40: 110 114

[52] Hurlstone DP, Sanders DS, Thomson M et al. "Salvage" endoscopic mucosal resection in the colon using a retroflexion gastroscope dissection technique: a prospective analysis. Endoscopy 2006; 38: $902-$ 906

[53] Ritsuno H, Sakamoto N, Osada T et al. Prospective clinical trial of traction device-assisted endoscopic submucosal dissection of large superficial colorectal tumors using the S-O clip. Surg Endosc 2014; 28: $3143-3149$

[54] Mizushima T, Kato M, Iwanaga I et al. Technical difficulty according to location, and risk factors for perforation, in endoscopic submucosal dissection of colorectal tumors. Surg Endosc 2015; 29: 133 - 139

[55] Toyonaga T, Man-i M, Chinzei R et al. Endoscopic treatment for early stage colorectal tumors: the comparison between EMR with small incision, simplified ESD, and ESD using the standard flush knife and the ball tipped flush knife. Acta Chir lugosl 2010; 57: 41 - 46

[56] Uraoka T, Ishikawa S, Kato J et al. Advantages of using thin endoscope-assisted endoscopic submucosal dissection technique for large colorectal tumors. Dig Endosc 2010; 22: 186-191

[57] Hisabe T, Nagahama T, Hirai F et al. Clinical outcomes of 200 colorectal endoscopic submucosal dissections. Dig Endosc 2012; 24: (Suppl. 01): $105-109$

[58] Hotta K, Shinohara T, Oyama T et al. Criteria for non-surgical treatment of perforation during colorectal endoscopic submucosal dissection. Digestion 2012; 85: 116 - 120

[59] Okamoto K, Muguruma N, Kitamura S et al. Endoscopic submucosal dissection for large colorectal tumors using a cross-counter technique and a novel large-diameter balloon overtube. Dig Endosc 2012; 24: (Suppl. 01): $96-99$

[60] Okamoto K, Kitamura S, Muguruma N et al. Mucosectom2-short blade for safe and efficient endoscopic submucosal dissection of colorectal tumors. Endoscopy 2013; 45: 928 - 930

[61] Nawata Y, Homma K, Suzuki Y. Retrospective study of technical aspects and complications of endoscopic submucosal dissection for large superficial colorectal tumors. Dig Endosc 2014; 26: 552 - 555

[62] Makino T, Kanmura S, Sasaki F et al. Preoperative classification of submucosal fibrosis in colorectal laterally spreading tumors by endoscopic ultrasonography. Endosc Int Open 2015; 3: E363-E367

[63] Lee EJ, Lee JB, Choi YS et al. Clinical risk factors for perforation during endoscopic submucosal dissection (ESD) for large-sized, nonpedunculated colorectal tumors. Surg Endosc 2012; 26: 1587 - 1594

[64] Yoon JY, Kim JH, Lee JY et al. Clinical outcomes for patients with perforations during endoscopic submucosal dissection of laterally spreading tumors of the colorectum. Surg Endosc 2013; 27: 487-493

[65] Hong MJ, Kim JH, Lee SY et al. Prevalence and clinical features of coagulation syndrome after endoscopic submucosal dissection for colorectal neoplasms. Dig Dis Sci 2015; 60: $211-216$

[66] Jung DH, Youn YH, Kim JH et al. Endoscopic submucosal dissection for colorectal lateral spreading tumors larger than $10 \mathrm{~cm}$ : is it feasible? Gastrointest Endosc 2015; 81: 614-620 
[67] Zhou PH, Yao LQ, Qin XY. Endoscopic submucosal dissection for colorectal epithelial neoplasm. Surg Endosc 2009; 23: 1546 - 1551

[68] Repici A, Hassan C, Pagano N et al. High efficacy of endoscopic submucosal dissection for rectal laterally spreading tumors larger than $3 \mathrm{~cm}$. Gastrointest Endosc 2013; 77: $96-101$

[69] Burgess NG, Metz AJ, Williams SJ et al. Risk factors for intraprocedural and clinically significant delayed bleeding after wide-field endoscopic mucosal resection of large colonic lesions. Clin Gastroenterol Hepatol 2014; 12: 651-661 e1-3

[70] Tanaka S, Haruma K, Oka S et al. Clinicopathologic features and endoscopic treatment of superficially spreading colorectal neoplasms larger than 20 mm. Gastrointest Endosc 2001; 54: 62-66

[71] Tamura S, Nakajo K, Yokoyama Y et al. Evaluation of endoscopic mucosal resection for laterally spreading rectal tumors. Endoscopy 2004; 36: $306-312$
[72] Su MY, Hsu CM, Lin C] et al. Endoscopic treatment of colorectal neoplasms: a simple and safe procedure to lower the incidence of colorectal cancers. Dig Dis Sci 2008; 53: 1297 - 1302

[73] Hurlstone DP, Sanders DS, Cross SS et al. Colonoscopic resection of lateral spreading tumours: a prospective analysis of endoscopic mucosal resection. Gut 2004; 53: $1334-1339$

[74] Terasaki M, Tanaka S, Oka S et al. Clinical outcomes of endoscopic submucosal dissection and endoscopic mucosal resection for laterally spreading tumors larger than 20 mm. J Gastroenterol Hepatol 2012; 27: $734-740$

[75] Tajika M, Niwa Y, Bhatia V et al. Comparison of endoscopic submucosal dissection and endoscopic mucosal resection for large colorectal tumors. Eur J Gastroenterol Hepatol 2011; 23: 1042 - 1049 